\title{
Representaciones del pasado, cultura personal e identidad nacional*
}

\author{
Alberto Rosa \\ Universidad Autónoma de Madrid \\ Guglielmo Bellelli \\ Università di Bari \\ David Bakhurst ${ }^{1}$ \\ Queen'ns University
}

Memoria, Historia, Individuo, Nación Identidad, - así, escritos con mayúsculas - son palabras que se hacen presentes en el discurso público de cada día. Se trata de conceptos que, en ocasiones, se convierten en armas arrojadizas en los conflictos sociales, y se agitan como conceptos explicativos en los discursos públicos que dan cuenta de la violencia simbólica, y a veces de la física, que sufren los ciudadanos de a pié; quiénes, además de ser peones en los juegos en marcha, no dejan de tener alguna responsabilidad en los resultados que en éstos se den.

El propósito de este capítulo es ofrecer un conjunto de conceptos y una estructura relacional entre ellos que facilite la conexión entre cada una de las aportaciones de que consta el volumen en su conjunto, al mismo tiempo que oferta una reflexión sobre una serie de cuestiones que, sin ser tratadas explícitamente en cada uno de los otros capítulos, muchas veces están presentes en forma de presuposiciones no siempre fáciles de tener en cuenta. Dicho en forma más breve, lo que aquí trataremos de ofrecer es un marco general de trabajo que, al mismo tiempo, contextualice los capítulos que siguen sobre el fondo de la preocupación contemporánea desde ámbitos disciplinares muy diversos sobre los temas citados al principio.

Las cuestiones que aquí nos van a ocupar, como es el caso de la memoria y la identidad, para ser abordadas con cierto rigor, requieren adoptar un planteamiento capaz de moverse ágilmente a través de las dimensiones espacio-temporales. A lo largo de este capítulo habremos de movernos necesariamente entre dos posiciones: la individual y la social; y entre dos maneras de tratar la dimensión temporal: la sincrónica y la diacrónica. Entendemos estas dos dimensiones como factores constitutivos del fenómeno humano que siempre tiene, simultáneamente, una naturaleza social (cultural) e individual (sostenida sobre acciones de organismos biológicos materiales), actual (determinada por las condiciones inmediatas presentes) e histórica (condicionado por su pasado y tendido hacia un futuro). A lo largo de este capítulo trataremos de tener en cuenta esta doble dimensión para dar cuenta de los fenómenos a los que nos vamos a dirigir. Por ello nos moveremos constantemente entre los polos de estas dos dimensiones.

\section{Planteando el problema:}

haciendo memoria para construir id entidad

Resulta ya un lugar común recordar que la identidad es imposible sin memoria. La

* Este texto foi originalmente publicado no livro: Memória colectiva e identidade nacional. Madrid: Biblioteca Nueva, 2000 (p. 41-87), organizado por Alberto Rosa Rivero (Facultad de Psicología, Universidad Autónoma de Madrid, Espanha), Guglielmo Bellelli (Departamento di Psicología, Università di Bari, Itália) e David Bakhurst (Departament of Philosophy, Queen'ns University, Canadá).

1. El presente capítulo ha sido redactado a partir de un borrador preparado por A. Rosa, al que se han añadido sugerencias de los otros autores. Agradecemos a F. Blanco, M. Diges yJ .A. Huertas sus comentarios sobre un borrador previo. 
identidad ${ }^{2}$ es un constructo, se refiere tanto a la sensación de un 'yo' permanente que perdura a través del tiempo a pesar de cambios (supuestamente) accidentales (yo soy el mismo en la foto de primera comunión, en la del servicio militar, o en esa otra en la que ya aparezco con el pelo blanco), como a la adscripción a una categoría (los conductores con carnet tipo B), 0 al sentimiento de pertenencia a uno u otro grupo (desde comunero en una comunidad de copropietarios - algo de lo que resulta relativamente fácil desafiliarse - hasta español - lo que resulta mucho más difícil de evitar). Pero el hecho de que la identidad sea un 'constructo' no la convierte inmediatamente en una entidad meramente imaginada, sino que llega a hacerse real a través de su influencia sobre las acciones que lleva a cabo el individuo biológico que es el sujeto de esa entidad. Uno no puede verse como algo (una entidad), sin considerarse a sí mismo como un ejemplar (id) de una forma de ser. La identidad es imposible sin la memoria, pero también sin alguna forma de conciencia. Si la identidad es un constructo, tenemos que explorar las bases sobre las que descansa. Para ello empezaremos examinando algunos modos en que los recuerdos del pasado contribuyen a la creación de identidad.

Para que una entidad pueda tener autoconciencia precisa de una representación de sí misma. Tal representación es tanto una imagen, un concepto de sí mismo, como un conjunto de recuerdos sobre su propio ser. Pero, además, lo primero es imposible sin lo último; por tanto, los recuerdos son lo primero en lo que nos tenemos que fijar.

Memoria, recuerdo y olvido: entre el individuo y elgrupo

Hay muchas maneras de fijarse en el modo en el que el pasado aparece en el presente, aquí nos vamos a detener sólo en algunas. Empecemos por fijarnos en cómo interactúan pasado, presente y futuro. Cualquier estado presente es una huella de lo sucedido en el pasado. Nuestro presente es lo que el pasado nos ha legado para construir el futuro con los recursos que el propio pasado nos dejó. En este sentido, el pasado nos resulta relevante en tanto que susceptible de hacérsenos presente ahora. De este modo, aunque nuestro mundo está restringido a experiencias presentes, algunas de las experiencias actuales que el entorno nos produce son susceptibles de actuar como significantes de acontecimientos del pasado. Nuestro sistema nervioso está construido también de una manera tal que registra huellas de los acontecimientos experimentados y pueda hacerlas accesibles cuando son precisas. Sin embargo, estas huellas del pasado no son registros fidedignos de lo efectivamente acaecido, sino las trazas que los eventos han dejado en la materia (viva o inerte) para ser interpretadas y utilizadas más adelante.

Dos son los tipos de huellas que aquí nos interesan: a) lo que las experiencias individuales dejan en la estructura física de los individuos vivos, y b) las huellas físicas que quedan en el mundo como consecuencia de las acciones de las fuerzas de la naturaleza, y entre ellas de los individuos y grupos humanos. Mientras las segundas resultan accesibles para cualquiera, las primeras sólo lo son de manera inmediata para la propia estructura individual en la que están inscritas. A estas huellas podemos llamarlas respectivamente memorias individuales y públicas; ambas están relacionadas, pero no debemos confundirlas. Las segundas no tienen significado a menos que resulten accesibles y sean interpretadas; a menos que se conviertan en experiencias memorables para individuos de carne y hueso.

La memoria, pues, nos hace accesible el pasado a través de procesos de recuerdo que son el resultado de la activación de huellas de

2 . La palabra 'identidad' tiene probablemente su origen en la combinación de varias palabras latinas idem (lo mismo) y entitas (entidad); es decir, la misma entidad a través del tiempo. Otra fuente etimológica es la palabra identidem (una y otra vez igual). (cfr. The Oxford Universal Dictionary Illustrated on Historical Principles, v. I, 1974; p. 1016). 
experiencias pasadas al servicio de acciones actuales. Pero también hay que tener en cuenta que los grupos humanos a través del tiempo han desarrollado procedimientos para ampliar la capacidad de mantener registros del pasado, más allá de la capacidad de registrar huellas en la propia memoria biológica corporal. Así surgieron sistemas de notación, poemas, historias, rituales o monumentos como formas de mantener la memoria, de hacer accesibles experiencias que caen mucho más allá del limitado espacio de tiempo de la vida de cada individuo. Estos artefactos hacen posible que un individuo acceda a la experiencia acumulada por el grupo. En otras palabras, hacen posible la cultura.

Esto que acabamos de decir tiene algunas consecuencias. Entre ellas está la transformación de la misma memoria natural, pues ahora resulta posible decidir qué aspectos del momento presente han de ser memorables para el futuro, con lo que ya la memoria no estaría formada únicamente por los rastros que el pasado dejó, sino también por aquellos aspectos de su presente que los contemporáneos de un evento decidieron que era conveniente registrar. La mediación de estos artefactos culturales, por otra parte, transforma los mismos procesos psicológicos de registro y recuperación de experiencias, que ahora ya no son sólo susceptibles de ser utilizados de una forma voluntaria, sino que toman una nueva estructura por los nuevos componentes (culturales, artificiales) que intervienen en ellos (vid. Leontiev, 1931; Bakhurst, 1990/1992).

Pero no hay que pensar que todas las memorias, todos los rastros del pasado se recuperan. Si antes decíamos que hay maneras de influir en los procesos de codificación, en el propio establecimiento de las huellas de experiencias presentes, que en el futuro serán huellas del pasado; también hay que tener en cuenta que sólo se recuerda aquello que sirve para algo en el curso de las acciones presentes. En ese sentido, el recuerdo es importante, pero también lo es el olvido, que en este sentido podríamos considerar como la no activación de los rastros del pasado existentes. Pero, además, como buena parte de las memorias que tenemos no son sólo rastros del pasado, sino también memorias de activaciones anteriores de esos rastros del pasado - es decir, recuerdos de anteriores actos del recuerdo - que contribuyen a mantener viva una parte de la memoria anterior, cuando una determinada memoria no se activa durante cierto tiempo, resulta cada vez más difícil activarla, quedando más y más en el pasado. En definitiva, va cayendo en el olvido, con lo que una parte de nuestro pasado nos resulta cada vez más remota y ajena. Esto que acabamos de decir resulta válido para cualquiera que sea el agente el recuerdo, ya sea éste un individuo o un colectivo.

Bartlett (1932/1995) decía que no hay memorias específicas almacenadas en la mente 0 en el cerebro, sino sólo trazos dejados por experiencias (esquemas) que se transforman cada vez que se activan para producir una experiencia concreta en el curso de una acción en marcha. Las memorias no son fijas, sino recreaciones del pasado que nos producen un sentido de continuidad, un sentimiento de ser una entidad con pasado y con futuro. Como dicen Barclay y Smith (1992), recordar implica: a) acceder a la información disponible como resultado de actividades cerebrales, b) reconstruir el pasado en el presente con algún propósito psicológico y social particular, y c) co(re)construir el pasado a través del recuerdo colectivo (en acciones de recuerdo compartidas) de acontecimientos personales e históricos y del relato de historias.

Recordar algo es, entonces, entretejer la experiencia de la activación consciente de esos trazos del pasado en el flujo de acciones actuales y, así, darles significado. De este modo, los recuerdos tienen un contenido y una forma; una forma que no es sólo una apariencia, sino un constituyente fundamental del propio recuerdo. El lenguaje y, a través de él, las jergas grupales, los géneros del habla, los recursos literarios, contribuyen a la forma que finalmente 
toman los resultados de los actos del recuerdo, particularmente cuando se comunican a otras personas. Se pueden recordar muchas cosas: experiencias personales, eventos reportados, 0 una mezcla de ambas cosas. Cuando los actos del recuerdo son al mismo tiempo actos de habla referidos a experiencias propias del hablante, hablamos de memorias individuales; cuando se refieren al pasado del grupo, las llamamos memorias sociales, y si éstas últimas cumplen algunos requisitos las llamamos historia. En cualquier caso, tanto unas como otras se muestran como un producto, como una producción lingüística de un autor (individual o colectivo) y, como tal, susceptible de ser sometidas a técnicas de análisis del discurso.

Las memoria colectiva ha sido un tema que ya trató J anet (1928) y, sobre todo, Hallwachs $(1925,1950)$, a partir del marco teórico de Durkheim. Según Hallwachs, cada grupo tiene su vida mental característica, dentro de la cual está su memoria colectiva distribuida en las actividades del grupo como tal, en cada uno de sus miembros, produciéndose procesos de memorización y de recuerdo en el grupo entendido como una entidad en funcionamiento. De hecho, para este autor toda la memoria humana tiene una naturaleza social, estando incluida en lo que él Ilamaba "marcos sociales de la memoria", de los cuales estudió los correspondientes a la familia, los grupos religiosos y las clases sociales. Bartlett (1932) continuó con el intento de conectar las memorias individuales y colectivas, con una línea de trabajo que ha sido continuada por otros muchos autores (cfr., p.e., Middleton y Edwards, 1990/1992).

Las memorias autobiográficas no son sólo memorias de experiencias propias, sino memorias que contienen información relativa al yo. Las memorias autobiográficas dan un sentido de coherencia, confortan intelectual y emocionalmente, además de compartirse con familiares, amigos y conocidos, entretejiendo nuestra vida personal con la de otros. Muchas de estas memorias se comparten con la cohorte generacional e incluyen referencias a eventos públicos importantes que afectan a nuestras vidas. Algunas de estas memorias reciben una atención pública especial, conservándose a través de rituales, representaciones gráficas, estatuas, edificios, etc. (Barclay y Smith, 1992).

Zinchenko (1939/1983) distingue dos tipos de funciones de recuerdo que resultan de interés en este contexto: la memoria involuntaria que se refiere a cuando el recuerdo aparece instrumentalmente en el curso de una acción con sus metas y motivos propios y que no está orientada al recuerdo; y la memoria voluntaria, cuando el recuerdo es el objetivo mismo de la acción. El recuerdo voluntario de las memorias autobiográficas puede darse en acciones individuales solitarias, para controlar sentimientos - consolarse en situaciones de ansiedad, 0 para activarse en situaciones de aburrimiento (Barclay Smith, 1992) - pero muchas otras veces esas acciones de recuerdo se producen en grupo, habiendo incluso objetos y prácticas sociales de recuerdo diseñadas específicamente para ello (vid. Radley, 1990/1992). Además, estas prácticas de recuerdo no se agotan en los actos de recordar, sino que tienen una propósito moral, cumplen la función de mover a la acción en una dirección particular, utilizando procedimientos de recuerdo particulares, que llegan a convertirse en símbolos, alcanzando una significación, un significado y un valor emocional particulares. De esta manera, las memorias autobiográficas se entretejen con las memorias sociales y con la historia, con las representaciones del pasado del grupo, tal y como aparecen en las narraciones y en los rituales. Así, los símbolos culturales se convierten en símbolos individuales con un valor emocional añadido.

Cultura públic a y cultura personal: de cómo la sociedad crea a la persona (y viceversa).

Barclay y Smith (1992) conciben esta conexión entre memorias autobiográficas y memorias públicas como la base para la construcción de una cultura personal conectada con una cultura pública. La cultura públi- 
ca puede caracterizarse como un conjunto de prácticas sociales y patrones de significado encarnados en símbolos. "La cultura personal es también un sistema de símbolos significantes (tal como las memorias autobiográficas) que sirven para almacenar y producir significado. La cultura personal, como la cultura general, consiste en un 'modelo de' y un 'modelo para' la producción de significados y realidades (...) y se crea en interacción para servir objetivos fisiológicos, psicológicos e interpersonales" (p. 76). Las culturas colectiva y personal se cruzan en la interacción personal, en las relaciones entre el individuo y los productos, prácticas e instituciones culturales. La corriente de realidad personal emerge dentro de la cultura personal donde ésta entra en intersección con la vida pública. Por supuesto, la realidad personal está hecha de experiencias fenoménicas que no pueden ser compartidas; sin embargo, cuando cultura pública y cultura personal entran en contacto, ambas se ven afectadas y se reestructuran aunque en grado variable. "Es en la interacción en marcha entre cultura pública y privada como se crea la realidad objetiva. La realidad objetiva puede ser un fenómeno construido, pero se construye en referencia a un mundo físico y social real que regula, corrige y conforma nuestras experiencias subjetivas" (Barclay y Smith, 1992; p. 77).

Si esto es así, nos encontramos entonces ante un cuadro en el que cultura pública y cultura privada se crean mutuamente, y la construcción de ambas es el resultado de un proceso de coconstrucción (Barclay y Smith, o.c.) entre las acciones del individuo y las interacciones con su ambiente social (ver también Valsiner, 1987). Las culturas individuales de los miembros de un grupo serían mucho más semejantes entre sí de lo que lo serían las de individuos que no comparten la misma cultura colectiva, al igual que lo sería también la 'realidad objetiva', en la que experiencialmente viven unos y otros, aunque para un supuesto observador imparcial ésta pudiera parecer como idéntica.

Obeyesekere (1981) sugiere dos procesos paralelos (objetificación y subjetificación) a los que Barclay y Smith (o.c.) recurren para explicar la co-construcción antes mencionada. La cultura personal se hace presente a través de la instanciación (objetivización), es decir, haciendo públicas memorias y emociones personales a través del habla y el movimiento. Esto se hace a través de recursos del lenguaje, con metáforas, formas narrativas y modos de expresión que la cultura pública suministra como herramientas para la expresión individual. La subjetivización, por su parte, es el proceso mediante el cual los patrones y símbolos culturales son tomados por la conciencia y reformulados para crear una imaginería subjetiva culturalmente tolerable, lo que Bartlett (1932) Ilamaba "convencionalización". Este proceso de subjetivización se produce a través de la internalización, especialmente a través de actos motores y del habla que primero se experiencian en el nivel interpsicológico y, después, intrapsicológicamente (Vygotski, 1978/1979; ver Bakhurst 1990/1992, para una discusión pormenorizada). De esta manera, si la cultura especifica valores, normas, sanciones, creencias y conceptos que amueblan la conciencia individual con un contexto para la atribución de significado a la experiencia, también, al mismo tiempo, plantea los términos en los que puede trabajar la memoria reconstructiva y la forma que ésta tomará. Si llevamos esto un poco más allá, podremos decir, también, qué 'yoes' conceptuales o recordados son posibles.

\section{Del Yo y la Identidad personal a la identidad social}

En psicología hay todo un conjunto de contribuciones que se dirigen a tratar de conceptualizar el yo y la identidad. Un tratamiento sistemático de las mismas resulta completamente fuera del objetivo de este capítulo (vid. Bakhurst y Sypnowich, 1995, para una discusión reciente); no obstante, vamos referirnos a algunos conceptos que nos van a resultar de utilidad para nuestro argumento.

G. H. Mead $(1909,1913)$ considera que los términos de referencia para el yo son resul- 
tado de las acciones de un agente biológico que, antes de tomar conciencia de sí mismo, ha de ser un actor en el mundo material. Es a través de las acciones sobre el mundo de este agente - en comunicación con los demás, a través de gestos, signos vocales y voces como los otros llegan a adquirir un significado para él. Pero, además, la idea de 'uno mismo' no puede surgir sin la idea del 'otro'. La conciencia de 'uno mismo' solamente emerge cuando el individuo es capaz de usar las voces que los otros utilizan para dirigirse hacia él y volverlas a usar uno para referirse a sí mismo.

En la terminología de Mead, el mí-mismo está formado por el yo y por el mí; el yo es el sujeto de la experiencia inmediata, pero que no aparece fenoménicamente en la conciencia; mientras que el mí es la experiencia de las acciones del yo, la autoconciencia que emerge de cada acción social de que es capaz el yo. Podríamos decir que cuando el yo habla, el mí escucha. Así, el mí-mismo sólo resulta posible cuando uno se convierte en el interlocutor de los actos verbales de uno mismo. Siguiendo esta tradición, podríamos decir que el yo hace posible tener experiencia (yo siento, pienso, actúo, padezco, etc.), y las memorias autobiográficas suministrarían la base fenoménica para el sentimiento del yo y para las ideas de mí y de mí mismo.

Fibush y Reese (1991) sugieren que una parte significativa de las memorias de la experiencia personal es el resultado de conversaciones sobre estas experiencias, que tienen la forma de narraciones, a través de las cuales los niños llegan a dominar el uso de las formas narrativas canónicas de la cultura pública en que se desarrollan. Csikszentmihaly y Beattie (1979) hablan de un 'yomismo' narrado, como un conjunto de historias, que transcurren en momentos temporales diferentes, que suministran explicaciones satisfactorias de la experiencia, con referencias a los criterios culturales aceptados. A partir de estas ideas Barclay y Smith (o.c.) sostienen la idea de que "esos recuerdos constituyen de hecho nuestra experiencia fenoménica del mí-mismo, especialmente del mí-mismo recordado, sin que se formen o tengan un significado originalmente dado por estar referidos al yo 0 al mí-mismo" (p. 81). Estas memorias adquie-ren significación personal a través de los procesos de objetificación-subjetificación que relacionan las culturas pública y privada. De esta manera, no hay un yo-mismo transcendental, sino una actividad orgánica que es la causa, y no el efecto, del yo-mismo. La propia forma que tenga el yo-mismo vendrá, entonces, conformada por las formas simbólicas presentes en la cultura del sujeto.

Ricoeur (1991) al referirse a la identidad distingue entre dos términos derivados de dos palabras latinas: idem ('igualdad') e ipse ('mismidad'). La igualdad se refiere al mantenimiento de la identidad de una cosa a través del tiempo $(a=a$ independientemente del tiempo transcurrido), mientras que la mismidad no es sólo un proceso de igualdad lógica, sino que presupone la existencia continua de un sujeto de la acción moralmente implicable, el mismo sujeto de la acción que permanece a través del tiempo. En cualquier caso, la identidad personal tienen conexión con la 'igualdad', al suponérsele una permanencia a través del tiempo, permanencia que sólo puede resolverse narrativamente, a través de un yo narrativo que pervive a través de los diferentes estados en que se narran las experiencias de esa identidad. La propuesta de Ricoeur es que la identidad es un proceso de autointerpretación mediado por estructuras sistémicas y narrativas; y como todo proceso interpretativo implica una dimensión moral, de imputación de responsabilidad, no de mera agencialidad.

Como dicen Rosa, Blanco, Huertas, Mateos y Díaz (1995), nuestro argumento es que términos como yo, mí, o mí mismo, son términos deícticos de actos del habla, actos que atribuyen agencialidad, que crean realizativamente una representación del sujeto, una entidad que aparece en la conciencia con una identidad personal (en sentido amplio) que corre a lo largo del tiempo. Tal identidad personal puede aparecer de

3 .En lo sucesivo utilizaremos indistintante los términos mi-mismo y yomismo para referirnos al término self que usaba Mead que carece de traducción directa al español. 
diversas maneras, p.e., como autoconcepto, como conjunto de atributos pertenecientes a diferentes clases, o como un yo o un nosotros narrativo, dependiendo de la forma en que aparezca en el discurso. En este sentido, la identidad personal o colectiva es resultado de discursos que son ellos mismos resultado de actos del habla de individuos que actúan con los recursos mediacionales que tienen disponibles. Actos del habla que, en tanto predican algo de un sujeto permanente, que lo identifican con una categoría, podemos, desde una psicología de la acción, denominar como actos de identi-ficación (Rosa y col., 1995).

La identidad, sin embargo, no es un concepto coincidente con el concepto de mímismo o con las memorias autobiográficas. La identidad relaciona a un sujeto con otros, considerándolos como compartiendo atributos - como pertenecientes a un mismo grupo (Turner, 1985; Turner y Oakes, 1986). De modo que el esquema del yo-mismo se relaciona con el del grupo, produciendo en el individuo un sentimiento de pertenencia a una entidad superior, compartiendo sistemas de valores, motivaciones y sistemas de categorización.

$\mathrm{Ni}$ que decir tiene que los actos de identificación están situados, es decir, se producen en contextos concretos, tienen su dramaturgia propia $y$, cuando al mismo tiempo son actos del habla, están dirigidos a interlocutores particulares y tienen una naturaleza inherentemente dialógica (Bajtín, 1981; Wertsch, 1991). Dicho de otra forma, no son actos que desvelen una forma de ser, sino que manifiestan la forma de estar de ese sujeto en ese momento determinado y ante las personas y las circunstancias ante las que se halla entonces. El plantearse lo que el sujeto efectiva y realmente sea, cuál es su auténtico ser, implicaría una concepción esencialista de la identidad y del sujeto psicológico que no compartimos.

\section{Estructurando el campo: de lo} individual a lo social

De lo que se ha dicho hasta el presente parece seguirse que una explicación psicológi- ca, por sí misma, no puede dar cuenta de algo tan complejo como la identidad nacional. Esto puede que sea verdad, pero ciertamente no es toda la verdad. Todas las ciencias sociales tienen un papel en este empeño, y en esta división del trabajo la psicología tiene también su papel, que no es otro que el de ofrecer una explicación, tan detallada como sea posible, de cómo los procesos psicológicos que se producen en los individuos proporcionan la base para un proceso social tan complejo. No hay duda de que la acción humana no puede ser explicada refiriéndose únicamente a lo que sucede de la piel para dentro (Wertsch, 1991), pues la agencialidad de la acción humana no es achacable únicamente al agente, sino que está distribuida también en el contexto. Pero eso no quita que para explicar lo que un individuo hace haya que mirar también a lo que sucede en el propio individuo biológico y psicológico.

La psicología científica, desde su propio inicio, trató de relacionar, pero también de distinguir, los procesos psicológicos básicos y los productos culturales. Ya Wundt (1912-13/1926) señaló que el lenguaje, la mitología, el arte, las costumbres y la religión son productos del esfuerzo humano colectivo y que "todos los fenómenos de los que tratan las ciencias psíquicas son productos de la colectividad" (p.2). El definió a la Psicología de los Pueblos como "investigaciones referidas a las relaciones que las cualidades intelectuales, morales y otras de orden psíquico de los pueblos en el respecto de las relaciones que guardan entre sí, y con el espíritu de la Política, el Arte y la Literatura" (p. 1).

Cuando se contempla la Psicología de los Pueblos de Wundt en el contexto de toda su producción, puede considerarse que su empresa fue diferenciar entre diferentes niveles de análisis (fisiológico, individual y cultural) y descubrir para cada uno de ellos los métodos y las unidades de análisis adecuados. La introspección experimental controlada fue el método para el estudio de la conciencia individual, y la Völkerpsychologie para el estudio de la cultura (Kim y Berry, 1993). 
Las ideas de Wundt no han sido demasiado bien valoradas. Mientras que algunos le han culpado de la separación entre lo cultural y lo individual en psicología, los historiadores de la psicología por mucho tiempo han presentado una visión de su obra tan centrada en su psicología introspectiva de la conciencia que seguramente él mismo hubiera rechazado. Pero puede ser que su intento de conectar estos tres niveles de análisis estuviera entre los elementos del Zeitgeist del momento que inspiró también la formulación de la aproximación histórico-cultural a la psicología. Vygotski y sus colaboradores desarrollaron una aproximación psicológica que trataba de superar los problemas metodológicos derivados de la aproximación idealista de Wundt, tratando también de explicar fenómenos que se producían a estos tres niveles, al mismo tiempo que trataban de interconectarlos entre sí. La contribución de Luria a este respecto es paradigmática.

Rosa (1994a; Rosa, Huertas y Blanco, 1993; Rosa y Simón, 1996) ha vuelto a esta idea de niveles de análisis interrelacionados, considerando también algunos desarrollos recientes en psicología y ciencias próximas, Io que le ha llevado a añadir un cuarto nivel de análisis a los tres mencionados anteriormente. Repasémoslos brevemente.

\section{EI suje to psicológico entre la naturaleza y la cultura: una}

propuesta de niveles de análisis

El primer nivel de análisis es el biológico; es decir, el que se preocupa de la materialidad de los seres humanos. La consideración de este nivel de análisis implica la necesidad de especificar las restricciones que impone el diseño estructural y funcional del organismo humano.

El nivel de análisis computacional se refiere a las operaciones llevadas a cabo por el aparato físico. Tal y como se contempla, no pretende estudiar la sintaxis de la manipulación de supuestos símbolos almacenados y manipulados en un dominio virtual denominado 'mente'; por el contrario, cumple el papel de un poderoso interfaz analítico entre los niveles de análisis biológico e individual, siendo sus unidades básicas de carácter subsimbólico, cruzando el umbral simbólico (y convirtiéndose así en psicológicas, semióticas, lingüísticas) cuando las redes neurales, sobre cuyo funcionamiento descansan, se activan en el transcurso de una acción individual (Smolenski, 1988). Hay que añadir que las descripciones matemáticas que se pueden ofrecer desde este nivel de análisis constituyen metáforas del funcionamiento de las propiedades funcionales del sistema nervioso. De

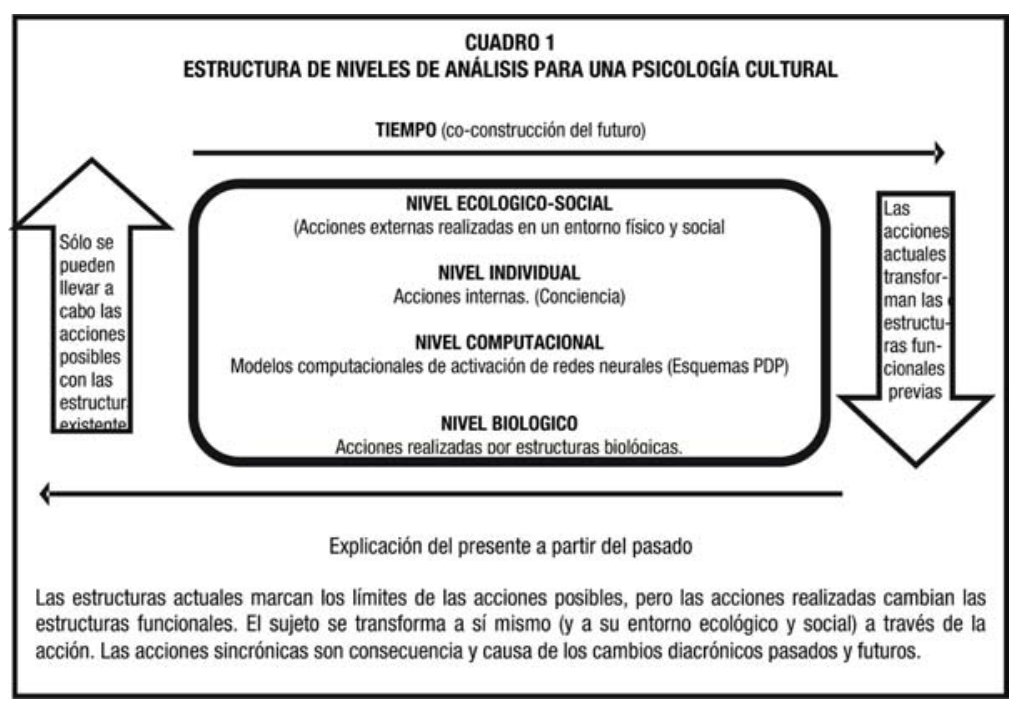


este modo, proponer un nivel de análisis computacional no implica ninguna forma de reduccionismo, sino que viene a ser una forma de especificar cómo la acción y el conocimiento pueden implementarse materialmente.

El nivel de análisis individual se preocupa de las acciones individuales, acciones que al mismo tiempo son internas y externas, objetivas y subjetivas y que resultan del funcionamiento de un aparato biológico con ciertas propiedades computacionales.

El nivel de análisis ecológico-social se refiere a las condiciones en las que se realiza la acción, además de a las demandas y ayudas ofrecidas por el entorno. Incluye las relaciones con el medio físico, interacciones sociales, comunicación, constructos culturales, condiciones institucionales, etc.; es decir, el marco en el que el sujeto vive y actúa.

Resulta particularmente importante señalar que estos cuatro niveles de análisis no son sino cuatro facetas de una entidad única: el individuo humano considerado como un organismo biológico actuando en un medio físico, social y cultural. De este modo, la misma acción puede ser descrita desde el punto de vista de cada uno de los niveles de análisis, de manera que desde cada uno de ellos se describan fenómenos y prediquen sistemas explicativos diferentes que deban ser tenidos en cuenta desde los niveles adyacentes; algo que merece un comentario más pormenorizado. Las operaciones que se describen desde cada nivel de análisis señalan los límites de las condiciones de posibilidad para las operaciones del nivel inmediatamente supraordenado, mientras que las operaciones que se llevan a cabo en los supraordenados, actualizan algunas de las posibilidades de cambio de los infraordenados (ver cuadro 1). Dicho de otra manera, las funciones son llevadas a cabo por estructuras, pero éstas mismas son productos de acciones anteriores. Una posición que reclama una aproximación dinámica y genética al fenómeno humano, que tenga en cuenta los cambios filogenético, histórico-cultural, ontogenético y microgenético.
Dado que desde cada nivel de análisis se aborda el mismo referente desde una perspectiva disciplinar diferente, los fenómenos que se describen desde cada nivel de análisis deben estar profundamente interrelacionados, de manera que desde fuera pueden aparecer como fenómenos isomórficos. La idea de sistema funcional desarrollada por Luria puede resultar instrumental como metáfora de una estructura isomórfica que toma una forma diferente en cada uno de esos ámbitos. Como el Laboratory of Comparative Human Cognition (1982) señala, no hay ninguna razón por la que la noción de sistema funcional tenga que mantenerse restringida al dominio biológico, también puede aplicarse al nivel de análisis computacional (vid. McClelland, Rumelhart y Hinton, 1986), al nivel de análisis individual (Luria 1932; Vygotski 1982a, 1982b), y al nivel ecológico-social (LCHC, 1982). Esta estructura isomórfica tiene una naturaleza sistémica y es el resultado de la colaboración simultánea de varias estructuras independientes pre- existentes que realizan juntas una acción concreta, lo que posibilita la aparición de propiedades emergentes cuando se observan simultáneamente desde los distintos niveles de análisis.

En cualquier caso, las acciones concretas que los sujetos humanos realizan sobre el entorno involucran a todos los niveles de análisis al mismo tiempo, razón por la cual no pueden ser considerados como entidades plenamente independientes, sino como meros instrumentos analíticos. Como señala Wertsch (1991), la acción llevada a cabo con instrumentos de mediación puede considerarse como la unidad de análisis para la psicología, pero debe tenerse en cuenta que esta unidad de análisis, como el mismo Wertsch señala, se extiende más allá del dominio de lo individual. Desde su punto de vista, la agencialidad de la acción se extiende más allá de la piel (Wertsch, Tulviste y Hagstrom, 1994) en una doble dimensión: por una parte en el dominio de lo interpsicológico - para dar cuenta de acciones cooperativas y colectivas, en las que hay más de un agente 
involucrado, como es el caso de fenómenos de cognición distribuida $-y$, por otra, en el plano cultural, porque incluso los actos individuales de sujetos aislados requieren del uso de recursos mediacionales de naturaleza cultural, lo que Cole (1999) denomina artefactos culturales. De este modo, las acciones concretas que llevan a cabo los individuos - actuando individualmente o de forma cooperativa - están restringidas (y utilizan los recursos suministrados) por el entorno físico, social y cultural en que se llevan a cabo.

Un enfoque sistémico como el que se acaba de presentar considera al sujeto mismo como un conjunto de sistemas mediacionales; es decir, como un conjunto de sistemas funcionales en interacción, que llegan a instanciarse de la piel hacia dentro, como consecuencia de las acciones realizadas sobre el entorno. Esto se produce a través de la instanciación y continua reactualización de esquemas (Bartlett, 1932; Rumelhart, Smolenski, McClelland y Hinton, 1986) o sistemas funcionales neuronales. Estos esquemas no son directamente observables, pero son susceptibles de inferirse a través de los resultados observables en acción, además de poder ser modelizados.

Esta visión del comportamiento de los sujetos humanos que acabamos de presentar creemos que tiene varias virtualidades. Por una parte, hace posible conectar las dos dimensiones espacio-temporales de las que hablábamos al principio del capítulo, pues integra tanto los aspectos sociales e individuales, además de armonizar la explicación sincrónica con los cambios diacrónicos que se dan en la propia estructura funcional individual. Por otro lado, hace posible integrar una teoría del significado (y del proceso de semiosis) al modo de Peirce (ver Apel, 1975/1997, Sheriff, 1989, para introducciones sistemáticas) en la que el significado aparece como un fenómeno emergente a partir de la acción orientada de un organismo (Riba, 1990, 1994), que cuando se aplica sobre artefactos culturales mediacionales (cfr. Cole, 1999) puede llegar a transformar a la acción misma convirtiéndola en consciente y haciendo emerger procesos psicológicos de naturaleza artificial (Vygotski (1982/1991a); además es compatible con la formación de nuevos conceptos artificiales (Vygotski, 1934), o con la construcción social de los cuasi-objetos de las ciencias sociales (Latour, 1991).

La memoria misma, la formación del esquema del mí-mismo, del que antes hemos hablado, o la consideración de un determinado significante como signo de la identidad propia, no son sino casos particulares del modo de funcionamiento del sujeto psicológico que acabamos de esbozar. Pero, además, esta manera de entenderlo nos lleva a considerar que cada cultura establece unas condiciones de posibilidad concretas para el desarrollo de un tipo de noción de sí-mismo, estableciendo, también, símbolos con determinadas capacidades de significación para sus miembros. Dicho de otra manera, la identidad personal y social son productos socio-culturales situados en el tiempo. La consideración de cómo se llega a generar la identidad nacional nos lleva a explorar las dimensiones sociales políticas de la vida institucional de los grupos humanos. Esa será la siguiente estación en nuestro camino.

\section{Vida política e identidad nacional}

Hasta ahora hemos estado hablando del concepto de identidad desde una perspectiva psicológica. Pero la identidad, como ya hemos señalado, no es un concepto que pertenezca en exclusiva a la psicología, sino que forma parte del patrimonio de todas las ciencias sociales. Dado que nuestro objetivo aquí es el tratamiento del concepto de identidad nacional, fijémonos ahora en algunas contribuciones realizadas desde la ciencia política.

\section{Nación, etnia, es tado y naciona lis mo}

Smith (1991) señala la omnipresencia actual de la nación como un elemento para la identidad personal. Este es un fenómeno global 
que nos resulta relativamente reciente, y que ha evolucionado a partir de la concepción occidental de nación moderna, aunque sus orígenes se encuentran en comunidades étnicas. Las etnias están mucho más extendidas, existen en todas partes del mundo y no necesitan de estructuras políticas para sobrevivir.

Una nación es "una población humana con nombre propio que comparte un territorio histórico, mitos comunes y memorias históricas, una cultura pública de masas, una economía común, así como derechos y deberes legales iguales para todos sus miembros" (Smith, 0.c.; p. 14). La nación tiene un carácter mítico, pues aparece como algo que ha existido siempre, lo que se ve reforzado por el hecho de que el pasado se hace presente de manera continua a través de la presencia de tradiciones que encarnan memorias, mitos y valores de épocas pasadas.

El estado se "refiere exclusivamente a las instituciones públicas, diferentes y autónomas de otras instituciones sociales, y que, además, ejerce el monopolio de la coerción y la extracción de impuestos dentro de un territorio dado. La nación, por otra parte, significa un vínculo cultural y político, que une a una única comunidad política que comparte una cultura histórica y un territorio patrio" (Smith, o.c.; p. 14-15). Como puede comprobarse, hay un cierto solapamiento entre estos dos conceptos; sin embargo, en la década de 1970 sólo un 10\% de los estados existentes podían considerarse como estados-nación.

El concepto de nación tampoco es totalmente independiente del de etnia. Una etnia es un tipo de comunidad cultural que enfatiza el papel de mitos de descendencia, costumbres, lenguaje 0 instituciones. También tiene un nombre para designarse a sí misma, existe un sentimiento de solidaridad entre sectores significativos de su población y se asocian con un territorio patrio, aunque puedan no vivir de hecho en él. Una etnia es autoconsciente de su propia identidad, pero los grupos que la constituyen son temporalmente contingentes (apareciendo, cambiando y disolviéndose), dependiendo de su memoria histórica para su supervivencia como grupo. Una categoría étnica comparte prácticamente las características anteriores, excepto la autoconciencia de su propia identidad, pues es designada como grupo desde fuera, sin que sus miembros se reconozcan como tales. (Smith, 1991).

El nacionalismo es una ideología que sostiene la legitimidad de las naciones y ayuda así a crearlas. Smith (o.c.) define el núcleo central de la ideología nacionalista de la siguiente manera: "1. El mundo se divide en naciones, cada una con su propia individualidad, historia y destino; 2 . La nación es la fuente de todo poder político y social, y la lealtad a la nación supera a toda otra lealtad; 3. Los seres humanos deben identificarse con una nación si quieren ser libres y realizarse a sí mismos; 4. Las naciones deben ser libres y sentirse seguras si se quiere que la paz y la justicia reinen en el mundo" (p.74). Este mismo autor subraya que el nacionalismo no reclama, como principio necesario y universal, que naciones y estados hayan de coincidir, pues en muchas ocasiones una nación (con sus partidos nacionalistas) puede sentirse cómoda dentro de un estado multinacional. Así considerado, el nacionalismo puede ser una ideología política con una doctrina cultural en su interior. El nacionalismo tiene como meta el mantenimiento de la autonomía, unidad e identidad de una nación.

\section{Desarrollo de la ideología naciona lis ta}

El mismo Smith nos ofrece un relato de los orígenes de esta forma de ideología. Según él los primeros orígenes hay que buscarlos en los escritos de Lord Shaftesbury sobre el "genio nacional", haciéndose común entre escritores del s.XVIII, como Montesquieu y Rousseau, la idea de un carácter y una identidad nacional.

J ohannes Gottfried Herder es considerado como el principal iniciador de una ideología de populismo nacionalista cuyo concepto central era el de Volkgeist ('espíritu del pueblo'), según el cual muchos individuos tenían el sentimiento de compartir la misma descendencia 
y territorio. Ese 'espíritu' común estaría influido por factores ambientales, educativos y por necesidades físicas y biológicas, y se comunicaría y compartiría a través del habla, la mitología, la religión, el folclore, el arte, la literatura, la moralidad, las costumbres y la ley; conformando la forma en la que la gente vive, se plantea metas, imagina, piensa y se comporta. Además, como se partía del supuesto de que toda actividad humana expresa toda la personalidad del individuo o el grupo que la ejecuta, su auténtico significado sólo sería accesible a los miembros de ese grupo, a través de un proceso de empatía (einfühling).

A estos ingredientes que constituyen ese supuesto "espíritu del pueblo", se añaden otros dos elementos, también de la tradición romántica. La idea de unidad de todos los miembros de la comunidad cultural - que los revolucionarios franceses denominaron fraternité - y el concepto kantiano de 'autodeterminación', que en su origen era un principio ético individual y que Fichte y Schlegel aplicaron al grupo, dando origen a una filosofía de autodeterminación nacional y de lucha colectiva al servicio de la voluntad nacional. Así entendido, el nacionalismo viene a significar la toma de conciencia que la nación y sus miembros hacen de su auténtico nosotros(yo)-mismo(s) colectivo. En definitiva, el nacionalismo como ideología ha sido el resultado de la labor de minorías intelectuales.

El nacionalismo es un producto de la modernidad y una respuesta a la crisis de identidad que supuso el intento de crear un 'estado científico' que reemplazara a las monarquías absolutas, a través de la substitución de la vieja legitimidad de la tradición y la religión, por otra nueva derivada del uso de la razón y de la observación científica. Esta crisis afectó profundamente a los intelectuales que hubieron de desarrollar conceptos alternativos, desarrollando nuevas mitologías y símbolos para fundamentar la acción y el pensamiento humano; lo que supuso intentar integrar el presente con el pasado y el futuro, sin recurrir a la creación sobrenatural o a una teleología divina en la
Historia. Tal como Smith (o.c.) lo plantea, a la pregunta de, ¿el pasado o el futuro de quién?, ¿de la humanidad como un todo, o sólo de algunas de sus partes individuales o colectivas?, se dieron diversas respuestas, que oscilaron entre el marxismo y el liberalismo, por una parte; 0 el nacionalismo y el fascismo racista, por otra.

En definitiva, nación y nacionalismo son productos de la historia y civilización europeas modernas, que han generado una ideología que sostiene la continuidad política entre el estado y el pueblo/nación. Mientras el nacionalismo - como un rasgo de mentalidad - es una actitud y posiblemente una emoción enraizada en la fusión entre uno mismo y su propio estado-nación; la identidad nacional va más allá, reclama un profundo vínculo existencial, naturalista, entre los ciudadanos de un país concreto a través de las líneas del ius sanguinis y dentro de una cosmología común de valores naturales. De este modo, los elementos formales del nacionalismo asignan características nacionales a los individuos como características personales que les son propias, una especie de moralidad, conducta, rasgos fenotípicos, destino personal subjetivo previsto. Mientras que el nacionalismo deja abierta la cuestión de cómo y por qué alguien adquiere una identificación nacional, y, por consiguiente, también la cuestión de la libre voluntad; la identidad nacional postula un destino común inexorable e inevitable, que une a los ciudadanos como un hecho de la na-turaleza, determinando normativamente sus lealtades y sentimientos morales. El discurso de la identidad toma la apariencia de un discurso sobre la naturaleza, inventando naciones y nacionalismos como necesidades psicosociales básicas y como inclinaciones biológico-culturales inherentes. (Hedetoft, 1995).

Es en este sentido en el que la 'identidad nacional' representa la mayor ficción de la unidad nacional, la ideología apolitizada de la comunidad política, su justificación étnico-racial. Es la ideología del estado para sus ciudadanos, estableciendo la raison d'être para su soberanía: el vínculo entre el 
estado y el pueblo que desafía a la razón y a la argumentación. Cuando este imperativo político se transforma en un indicativo colectivo e individual ('por supuesto que todos amamos a nuestro país'), que es aceptado por todo el pueblo como sentido común y mentalidad cotidiana, entonces se convierte en la sacralidad profana de la vida contemporánea. (Hedetoft, 0.c.; p. 27)

\section{La nación como pacto de intereses y plebis c ito diario}

Pero si el nacionalismo, y cada una de las naciones, se han originado en el pasado y han ido evolucionando hasta su forma presente, su existencia cotidiana no puede explicarse simplemente recurriendo a una supuesta inercia histórica. Como indica Hedetoft (o.c.)

La Historia es, sin duda, la sede principal de las condiciones necesarias para el nacionalis- mo, pero parece que no podemos, sin caer en una imposible e insostenible circularidad, sostener simultáneamente que también nos suministra todas las razones necesarias, y no digamos sus formas, sustancias y argumentos. Si [...] la existencia de una nación es un plebiscito diario, es la naturaleza de la volición que subyace al voto afirmativo de la gente lo que en último término hace que la nación sea la culminación de un largo pasado de empresas, sacrificio y devoción. (p. 11)

Si hasta ahora hemos dado por supuesta la existencia de estados, etnias y naciones, además de haber esbozado cómo surgió la ideología nacionalista, ahora vamos a fijarnos en el modo en el que la ideología nacionalista se encarna diariamente en una identidad nacional. Algo que tiene que ver con el modo en el que se ordena la vida colectiva, con el modo de armonizar los intereses particulares de los miembros de la comunidad, así como en el establecimiento de

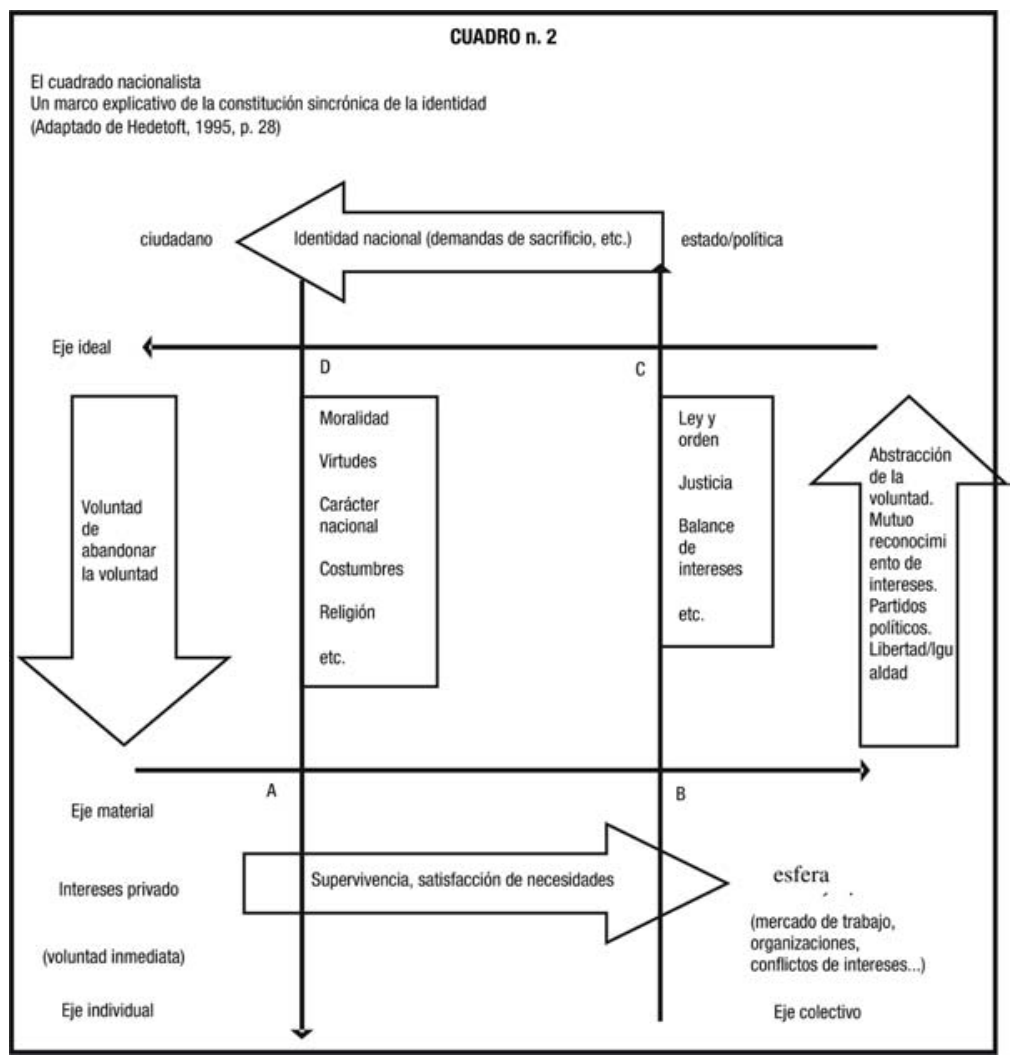


intereses y motivos colectivos. El cuadro n. 2 ofrece un esquema de cómo el nacionalismo combina discurso público y sentimientos privados, intereses materiales e ideales morales.

Este cuadro trata de esquematizar los componentes y el proceso mediante el cual se produce el tránsito desde los intereses materiales individuales a los colectivos, por un lado, para pasar enseguida al establecimiento de estructuras políticas (colectivas), y cómo de éstas se pasa a la construcción de la identidad colectiva individual, llegando finalmente a transformarse los esquemas motivacionales individuales a través de la pertenencia a la comunidad política. Este cuadro debe leerse en la dirección $A, B, C, D, A$; siguiendo un proceso de sucesivas abstracciones de los motivos y voluntades individuales hacia el establecimiento de un conjunto de condiciones objetivas. Hedetoft distingue los siguientes pasos en este proceso:

Primero: El estado como instrumento defensor y sostenedor de los intereses individuales, representado por los tramos A-B y B-C. El primero de ellos representaría la aceptación de que el interés de cada uno se ve limitado por los intereses de otros compatriotas, lo que conduciría a una especie de pacto social para someterse y regularse por un poder común. El tramo B-C se refiere al proceso mediante el cual los distintos miembros y grupos se reconocen como miembros del mismo matrimonio de conveniencia, estableciéndose mecanismos de organización e institucionalización de la vida política (p.e., partidos políticos). Esto implica reconocer que la voluntad propia ya no está en nuestras manos, sino en las de una entidad política externa. Esto implica, tanto reconocer a un 'otro' doméstico, como concebirse a uno mismo y a sus intereses de una forma diferente; es decir, reconocer y endosar la voluntad general. La abstracción voluntaria de la libre voluntad que se da en el eje B-C ya contiene la simiente de la mentalidad de solidaridad y sacrificio que caracteriza a fases posteriores de la identidad nacional.

Segundo: El sujeto se da cuenta de que las ventajas de la organización social no se materializan en una inmediata satisfacción de necesidades, pues tener derechos no quiere decir que se puedan ejercitar satisfactoriamente. La reacción no suele ser achacar los fallos a un sistema imperfecto, sino a fallos en el funcionamiento del sistema. Son los tramos B-C y C-D. Para los ciudadanos la voluntad politizada es, en principio, su voluntad y les gustaría que fuera útil para ellos mismos, es decir, entender la voluntad colectiva más como extensión de la voluntad propia que como una limitación de la misma. Su identificación con el estado depende de las consecuencias para uno mismo, y su apoyo al estado es más concreto que difuso, más cognitivo que afectivo, más cívico que étnico.

Tercero: (movimiento C-A) se rompen las amarras instrumentales entre el ciudadano y el estado y se instituye otro tipo de instrumentalidad en el proceso. La preocupación por la utilidad del estado se traduce en una preocupación por el mismo estado. El estado se contempla ya como 'nación', una entidad con un fin en sí misma. La identidad de intereses se eleva ahora a un plano ideal. Mis intereses son los mismos que los del estado, que entonces tiene mi apoyo incondicional. Aparece el orgullo de la afiliación nacional. La nación suministra un salario emocional, al mismo tiempo que se demanda a la nación que sea un honorable representante del ciudadano en la escena internacional. Ahora el estado político se convierte en estado natural, se convierte en una ontología, con formas de ser existenciales, esenciales y sagradas. La nacionalidad se ha convertido en identidad. El interés material de las fases anteriores se convierte ahora en desin-teresado y emotivo idealismo. Aquí es donde se hacen relevantes el 'otro' internacional, así como la xenofobia, los estereotipos del extranjero, además de la capacidad de sacrificio por el propio país.

Hedetoft sostiene que la ruta que acabamos de exponer retraza el proceso de formación de la mentalidad nacional. Una vez recorrido el círculo completo, cada uno de los tramos se 
presuponen e implican mutuamente, formando una red que entrelaza aspectos motivacionales, estructuras sociales, representaciones cognitivas y aspectos afectivos y emocionales, que incluyen mitos de origen nacional, historias de heroísmo y concepciones del 'otro' (el que resulta imprescindible como interlocutor para la construcción del 'nos-otros') como un ser siempre amoral. En definitiva, se establece un marco mental que hace posible que la gente acepte sacrificios y hasta vaya a la guerra. $Y$ todo ello alimentado por mitos diseminados en los sistemas nacionales de educación que son movilizados por la retórica política.

\section{De la ideología na c iona lis ta a I na c iona lis mo}

banal: la semiótica de la identidad nacional.

Esta ideología se hace expresa en formas que han llegado a impregnar de tal manera nuestra vida colectiva que resultan invisibles de puro obvias.
Estos conceptos - autonomía, identidad, genio nacional, autenticidad, unidad y fraternidad - forman un lenguaje trabado 0 discurso que se expresa a través de símbolos y ceremoniales, que están tan presentes en el mundo en que vivimos que los damos por supuestos. Incluyen los atributos aparentes de las naciones - banderas, himnos, desfiles, moneda, capitales, juramentos, vestidos tradicionales, museos de folclore, monumentos de guerra, ceremonias de recuerdo de los caídos por la patria, pasaportes, fronteras - además de otros elementos ocultos como las fiestas nacionales, el paisaje, los héroes y heroínas nacionales, los cuentos infantiles, las fórmulas de cortesía, los estilos arquitectónicos, la artesanía, los modos de construir las ciudades y de ordenar el territorio, los procedimientos legales, las prácticas educativas, los códigos militarestodas esas costumbres distintivas, estilos y modos de actuar y sentir que se comparten
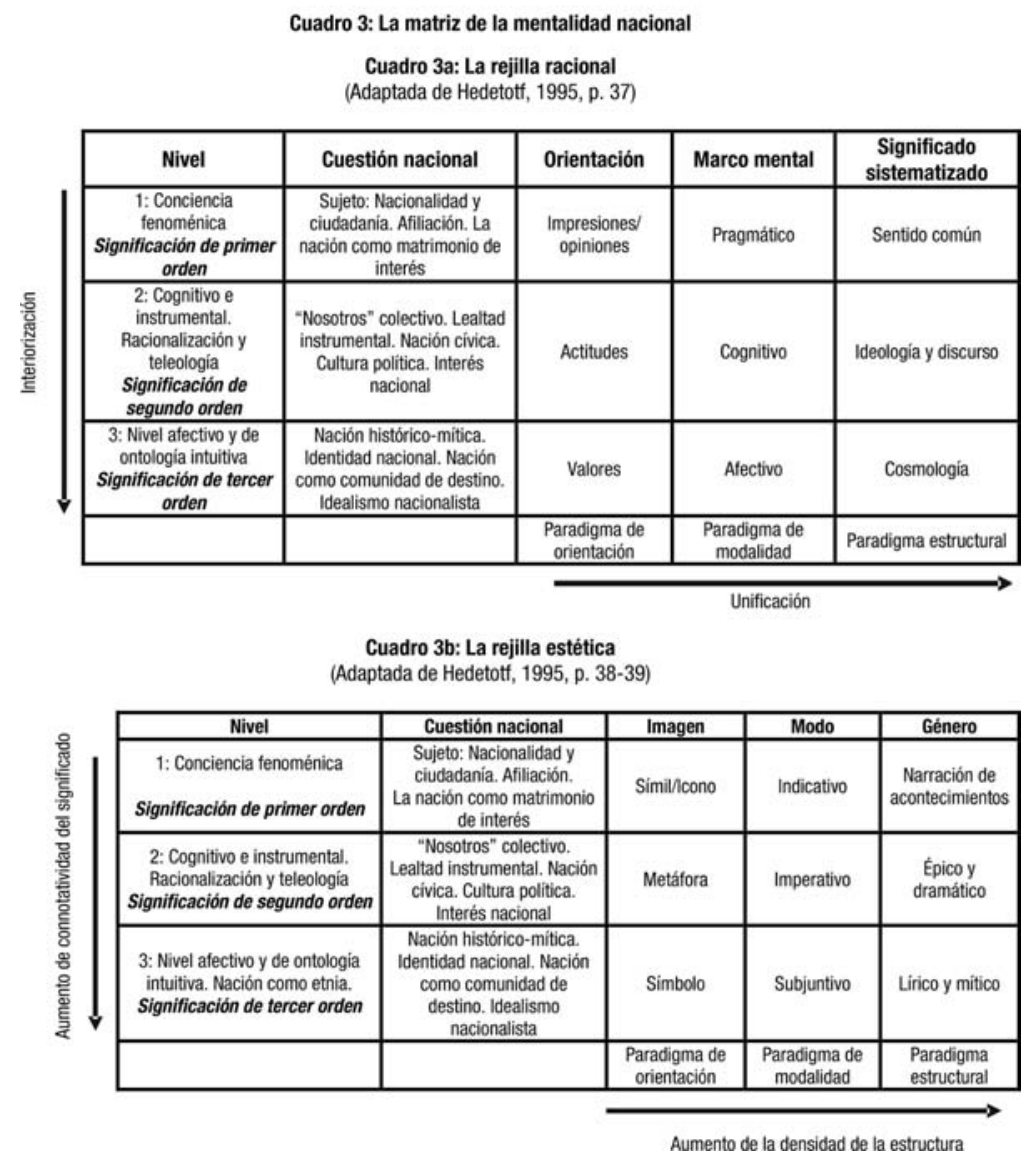
por parte de los miembros de una comunidad cultural e histórica.

En muchos aspectos los símbolos, costumbres y ceremonias nacionales son los aspectos más potentes y permanentes del nacionalismo. Encarnan sus conceptos básicos, haciéndolos visibles y claros para todos los miembros de la comunidad, comunicando los preceptos de una ideología abstracta en términos concretos y palpables que evocan respuestas emocionales instantáneas en todos los estratos de la comunidad" (Smith, 0.c., p.77).

En definitiva, la simbología del nacionalismo se hace presente en formas aparentemente inocuas y banales (Billig, 1995), pero, precisamente por ello, como siempre sucede con el uso experto de las formas retóricas, mucho más eficaces (Billig, 1987).

Fijémonos ahora en una explicación de cómo se transmite tanto la ideología nacionalista, como la identidad nacional. En definitiva, cómo elementos de la cultura pública llegan a convertirse en elementos constitutivos de la cultura personal de los nacionales de un determinado país.

Para que tal cosa pueda llegar a produ-cirse son precisas varias cosas, por un lado, un conjunto de iconos, símbolos y signos susceptibles de tener un significado público; y, por otro, un conjunto de prácticas compartidas del recuerdo (y del olvido) que involucren activamente a los individuos y hagan que esos significados públicos alcancen un sentido personal en la propia fenomenología de su conciencia. Veamos cada uno de estos dos aspectos sucesivamente.

Hedetoft (o.c.) entiende que una semiótica política del nacionalismo debe entenderse como el estudio de los signos y estructuras de significación que entretejen una variedad de vínculos 'verticales' entre el estado y la nación (los poderes y el pueblo) y 'horizontales' entre diferentes partes de la nación entre si. En último término, estableciendo relaciones muy estrechas entre a) cada 'mí- mismo' personal (nivel fenomenológico), b) la nación entendida como un 'nosotros colectivo' (con la cual se siente una identificación instrumental e imperativa: nivel racional y teleológico) y c) la identidad nacional, como una relación afectiva y simbólica con la nación como una entidad natural con una unidad mítica (nivel ontológico).

A partir de estos tres niveles, y jugando al mismo tiempo con elementos de la semiótica (y la ontología) de Peirce, Hedetoft (o.c.) nos presenta lo que denomina matriz de la mentalidad nacional, que esquematiza las estructuras semióticas a partir de las cuales entiende que se establecen las fenomenologías, teleologías y ontologías del nacionalismo. Esta matriz está compuesta por dos rejillas interrelacionadas que él Ilama Rejilla racional y rejilla estética, respectivamente (ver cuadro 3 a y b) cuya relación mutua es la de significado-significante, y de denotación-connotación, pero que también se separan, hablan con voces diferentes, se contradicen entre sí, y producen interesantes significaciones nuevas a niveles superiores.

Cuadro 4: Prácticas sociales de recuerdo

Adaptado de Rosa (1994b) y Rosa, Huertas y Blanco (1996)

\begin{tabular}{|c|c|c|c|c|}
\hline Tipo de práctica & Materia prima & Producto & $\begin{array}{c}\text { Función social y } \\
\text { personal }\end{array}$ & Criterios de verdad \\
\hline $\begin{array}{l}\text { Prácticas sociales } \\
\text { del recuerdo }\end{array}$ & \begin{tabular}{|c|} 
Relatos de recuerdos \\
personales o historias relatadas. \\
Monumentos, iconos, ritos, etc. \\
Relatos populares. \\
Mitos. Ficción literaria de \\
género histórico. Cine, teatro, \\
música. etc.
\end{tabular} & $\begin{array}{l}\text { Imágenes. } \\
\text { Relatos sobre el pasado. }\end{array}$ & $\begin{array}{l}\text { Representación del } \\
\text { pasado. } \\
\text { Interpretación del } \\
\text { presente. Producir } \\
\text { experiencias } \\
\text { emocionales. } \\
\text { Compartir social. }\end{array}$ & $\begin{array}{l}\text { Utilidad justificativa de la } \\
\text { identidad personal y } \\
\text { social. } \\
\text { Sostenimiento de la } \\
\text { moral social. }\end{array}$ \\
\hline $\begin{array}{c}\text { Asignaturas de } \\
\text { historia en la } \\
\text { enseñanza } \\
\text { obligatoria } \\
\end{array}$ & \begin{tabular}{|c|}
$\begin{array}{c}\text { Productos de la práctica } \\
\text { nistoriográfica. } \\
\text { objetivos politico-ideológicos de } \\
\text { la enseñanza. }\end{array}$ \\
\end{tabular} & $\begin{array}{c}\text { Relatos sobre el pasado. } \\
\text { Discursos indicativos, } \\
\text { imperativos y subjuntivos } \\
\text { sobre la identidad nacional. }\end{array}$ & $\begin{array}{l}\text { Ejercitar la identidad } \\
\text { personal y grupal }\end{array}$ & $\begin{array}{c}\text { Utilidad para la } \\
\text { orientación de la acción } \\
\text { colectiva futura } \\
\text { considerada como útil. } \\
\end{array}$ \\
\hline $\begin{array}{l}\text { Historiografia } \\
\text { Ciencia histórica }\end{array}$ & $\begin{array}{l}\text { Rastros fisicos del pasado. } \\
\text { Documentos } \\
\text { Productos historiográficos } \\
\text { previos. } \\
\text { Conocimientos de ciencias } \\
\text { auxiliares }\end{array}$ & $\begin{array}{l}\text { Constructor historiográficos. } \\
\text { Narraciones históricas }\end{array}$ & $\begin{array}{c}\text { Proyecto de futuro. } \\
\text { Conservación e } \\
\text { interpretación de la } \\
\text { experiencia acumulada. }\end{array}$ & $\begin{array}{l}\text { Criterios cientificos de } \\
\text { verdad. }\end{array}$ \\
\hline
\end{tabular}


Hedetoft (o.c.) señala que estas matrices deben tomarse como un marco abstracto interpretativo, más que como una camisa de fuerza. Por otra parte, estas matrices permiten diferenciar entre la cultura y las tradiciones (nivel 1 y 2) y la identidad nacional (nivel 3). Como regla general, los estados mentales que surgirían en la parte superior izquierda de las tres últimas columnas de cada matriz representan vínculos relativamente superficiales entre sujeto, nación y estado; mientras que la intensidad, unidad y estructuración del vínculo se va haciendo mayor al moverse hacia la esquina inferior derecha, donde el nacionalismo alcanzaría su culmen. La esquina superior derecha, por ejemplo, representa una especie de nacionalismo de sentido común, sostenido por una narración del estilo 'es natural que me sienta español, pues he nacido en España, hablo español y, además, soy español'.

Hedetoft nos indica, también que si el nacionalismo fuera un verbo se declinaría en tres modos: indicativo ('nosotros somos una nación'), imperativos ('nosotros/vosotros tenemos/tenéis que ser una nación'), y subjuntivo ('ojalá fuéramos una - mejor- nación'); modos que, como paradigma conceptual se refieren a tres tipos de relación entre estado y nación: a) estados nacionales (como en Europa occidental), b) estados sin naciones (como en África), y c) naciones sin su (propio) estado (p.e., los kurdos, los palestinos). Pero, como fenómenos mentales, estas modalidades no se excluyen entre sí, sino que están en un estado de continua interacción dentro de cada nación (y con frecuencia dentro de cada ciudadano), aunque su peso relativo varía de una nación a otra y de una situación a la siguiente. En todas las naciones-estado el patrón configuracional concreto depende de la fuerza de un número de variables y de su interacción, variables que son reducibles a un número limitado de signos-pivote que él denomina los topoi de repre-sentación nacional, considerándolas como las columnas maestras del edificio del nacionalismo. Estos actúan, solos o en combinación, como vínculos salientes entre el estado y la nación, como formas de demarcación nacional, identificación y orgullo, y son, además, formas básicas de exclusión y excepcionalidad nacional. Entre ellos estarían Guerra, Etnia, Deporte, Inmigración, Lenguaje, Territorio y Fronteras. Aunque cada uno de ellos tiene su especificidad, vienen a ser el ámbito donde se ejercita la identidad nacional, tanto en el plano público como en el privado.

Una vez que ya hemos repasado, siquiera someramente, los mediadores semióticos para la transmisión de la ideología nacionalista y la constitución de la identidad nacional, pasemos ahora a referirnos a algunos de los procedimientos y prácticas sociales en cuyo seno se utilizan.

\section{Historia, memoria social y representaciones sociales del pas ado}

A lo largo de este capítulo hemos venido refiriéndonos a diferentes procedimientos mediante los cuales los grupos y las sociedades conservan sus recuerdos, ya sea en forma de símbolos o en forma de prácticas sociales, algunas de las cuales están específicamente diseñadas para el recuerdo (ritos, desfiles, procesiones, homenajes, peregrinaciones, fiestas religiosas, cívicas o gremiales, etc.), con la peculiaridad de que estos recuerdos tienen un carácter voluntario (en la terminología de Zinchenko, o.c.), pero una utilidad volcada hacia el presente. Se trata de recordar el pasado, pero porque tiene alguna utilidad para el presente y el futuro.

Estas formas públicas de rememoración vienen acompañadas con formas privadas, pero también colectivas, de compartir el recuerdo, como es el caso de las visitas familiares a los cementerios, las historias familiares compartidas, las reuniones de antiguos alumnos, etc. En estos entornos se evocan experiencias compartidas y se transmiten a otras cohortes generacionales, típicamente en la forma de narraciones e interpretaciones. J unto a estas formas de recuerdo colectivo se dan otras de carácter más institucionalizado, como es la Historia. 
El cuadro n. 4 establece una clasificación de algunas de estas formas sociales de memoria.

Varios aspectos de este cuadro precisan de comentario aclaratorio. La primera columna diferencia entre dos acepciones de historia que creemos interesante distinguir, pues tanto la materia prima como los criterios de verdad que se manejan en uno y en otro caso son distintos. Mientras que las asignaturas de historia tienen una función instrumental (subordinadas a finalidades identitarias e ideológicas), la Historia en tanto saber disciplinado sigue criterios de verdad propios de disciplinas científicas, sin que por ello pueda evitar los sesgos propios de la función que toda práctica del recuerdo cumple tanto en el plano social como en el personal. La diferencia más notable entre la Historia disciplinar y los otros tipos de prácticas del recuerdo que aquí mencionamos es la validez de los productos que ofrece, cuya garantía de verdad reside (como en el caso de cualquier otro saber disciplinado) en el juicio de la comunidad científica de los historiadores profesionales. El grado de veracidad de los relatos ofrecidos por las asignaturas de historia se ve fuertemente afectado por la necesidad de abreviación de sus contenidos, además de por los objetivos de sus programas, por no citar otras posibles fuentes de sesgos que al lector le resultarán obvias. Por otra parte, la función social y personal de toda práctica social del recuerdo, independientemente de su veracidad, es la misma. Algo que conviene tener en cuenta de cara a la discusión que venimos realizando.

\section{Las narraciones producto de las práctic as sociales de recuerdo}

Uno de los productos comunes que aparecen en todas estas prácticas sociales del recuerdo son narraciones sobre el pasado. Independientemente de que éstas tengan un carácter público o familiar, o de que provengan de prácticas disciplinadas 0 no, tienen en común la forma narrativa (cfr. Wertsch, 1997) $y$, con ella, algunas características formales que no resultan irrelevantes. En primer lugar, una narración no sólo tiene un contenido (los eventos que relata), sino también una trama, la cual ella misma interpreta lo relatado como, por ejemplo, una comedia, una tragedia o una sátira (Gergen y Gergen, 1984; White, 1973); además, transmite una manera de entender el cambio histórico (Pepper, 1942/1966; White, 1973), implica un cierre narrativo (Albert, 1984) que no es ajeno a una consecuencia moral (Mathien, 1991), ni a una ideología (Mannheim, 1946; White, 1973). De este modo, cualquier narración - y con mucha más razón si pretende relatar acontecimientos realmente sucedidos en el pasado - implica una moral, señala una utopía a alcanzar o un peligro a evitar, de manera que incluye un componente ideológico, una dimensión final, una cierta filosofía de la Historia, si no en el contenido, ciertamente sí en la forma, lo que muchas veces es un recurso retórico mucho más eficaz.

Si estas prácticas de recuerdo producen narraciones, que no pueden evitar tener las características que acabamos de señalar, no tiene nada de particular que las (re?)construcciones del pasado que se ofrecen sean susceptibles a ciertas distorsiones a lo largo del tiempo, pues estas narraciones no son productos estáticos, sino que son reproducidas, combinadas, repetidas, etc. en el curso de la interacción interpersonal y de la vida cultural del grupo.

\section{Dis torsiones en el recuerdo colec tivo}

Los grupos, al igual que los individuos, utilizan los recuerdos para fines identitarios, lo que hace que en ocasiones su memoria se vea distorsionada para mantener una buena imagen de sí mismos. Baumeister y Hastings (1997) repasan algunas de estas formas de distorsión que se dan de manera sistemática.

La primera de ellas es el autoengaño (más o menos intencional), como es el caso, por ejemplo, de la negación del Holocausto. Cuando se da este fenómeno de negación del pasado las colectividades reaccionan de maneras muy diversas, desde tolerarlas, al considerarlas como una 
consecuencia indeseada del derecho a la libre expresión, hasta perseguirlas y prohibirlas, como sucede, por ejemplo en la Alemania contemporánea. Sin embargo, no parece que pueda darse el efecto contrario: obligar por ley a recordar de manera sistemática acontecimientos en los que uno, o su grupo, resultan con una imagen no muy buena. Más bien parece que en estos casos la tendencia dominante va hacia el olvido; es decir, la omisión selectiva de los acontecimientos desagradables.

En ocasiones se producen invenciones de acontecimientos pasados, más bien en la forma de acontecimientos míticos sin base histórica, si bien esto suele producir la denuncia de los historiadores profesionales. Lo que resulta más difícil de combatir es el coger algunos retazos de verdad y, con ellos, construir un mito útil para justificar la imagen del grupo (p.e., la 'explosión/voladura' del crucero USS Maine en la bahía de La Habana y sus diferentes interpretaciones en España y en los EE.UU.).

Otro procedimiento es la manipulación de asociaciones entre acontecimientos. Dado que muy frecuentemente los acontecimientos reales responden a una causalidad múltiple, puede exagerarse una de las conexiones causales, minusvalorando otras (p.e., la contrapuesta manera de entender la "liberación" de una ciudad por parte de una fuerza militar. ¿Quién liberó Manila?, ¿las tropas norteamericanas cuando sustituyeron a las españolas en 1898?, ¿las japonesas cuando expulsaron al poder colonial norteamericano?, ¿las norteamericanas cuando derrotaron a los invasores japoneses en la 2 Guerra Mundial?, ¿los mismos norteamericanos cuando evacuaron la ciudad tras conceder la independencia?, ¿los filipinos cuando lograron su independencia?). También se pueden observar mecanismos como la proyección de la culpa propia sobre el enemigo (p.e., 'las bombas atómicas de Hiroshima y Nagasaki están justificadas por el ataque a Pearl Harbour'); 0 el pasar la responsabilidad a las circunstancias 0 al marco contextual (p.e., 'fue la gripe la que mató a los amerindios').
En definitiva, de nuevo nos encontramos con que la memoria no sólo es recuerdo sino también olvido. Pero ni el uno ni el otro son accidentales; más bien lo contrario: ambos están motivados, lo que no quiere decir que necesariamente sean resultado de una decisión consciente y voluntaria.

Seguramente al lector avisado no se le habrá escapado que en este apartado hemos venido utilizando un léxico que presupone un enfrentamiento entre 'lo que realmente sucedió' y las 'distorsiones' de la memoria colectiva. Como ya habrá supuesto se trata de una continuación del argumento desarrollado en el apartado anterior respecto a los criterios de verdad manejados por los relatos sobre el pasado de la memoria colectiva y las narraciones históricas de los historiadores. Ambos productos discursivos coexisten en la vida social, por lo que debemos fijarnos en los modos en que interactúan.

\section{¿Memoria colectiva o representaciones sociales del pasado?}

Parece, pues, que en una sociedad existen un conjunto de registros del pasado, junto con todo un mare magnum de símbolos, imágenes, explicaciones y relatos sobre lo acontecido en el pasado, sobre la justificación del presente y sobre el futuro que desear, temer, luchar para conseguir, etc. La imagen que de esto resulta, se parece más a la de un confuso galimatías de voces a las que unos y otros concederían mayor o menor credibilidad o autoridad en función de los intereses de cada uno en cada momento; que a la de un proceso regido por una legalidad susceptible de análisis y explicación racional.

Este proceso al que acabamos de referirnos tal vez pueda describirse con la metáfora de un "mercado simbólico" (Bourdieu, 1991). Un mercado en el que distintos productos simbólicos se ponen a la disposición del público; productos que son comprados (consumidos mediante la inclusión en las propias acciones simbólicas de los 'clientes'), y que reciben mayor o menor va- 
Ior (crédito de verdad, o valor de uso) en función del consumo que de ellos se hagan. De esta manera, el consumidor de los productos simbólicos influye sobre el propio proceso de producción, mediante la atribución de un mayor o menor valor de verdad (o de uso) a estos productos (cfr. de Certeau, 1980/1984).

En un mercado como el que acabamos de describir no todos los productos tienen el mismo valor, pues éste depende tanto de la oferta, como de la demanda. Cuando nos encontramos con procesos de producción y transmisión de recuerdos tan variados como las producciones de los departamentos de historia en las universidades, los recuerdos de la abuelita, o una peculiar interpretación de un acontecimiento del pasado que hace un artículo periodístico al hilo de un suceso contemporáneo, podemos plantearnos si realmente nos hallamos ante un solo mercado simbólico 0 , más bien, ante toda una maraña de ellos que, en unas ocasiones se solapan entre sí, $y$ en otras son casi completamente independientes. Lo que sí parece indudable es que en un determinado espacio social se mueve una importante cantidad de productos simbólicos referidos al pasado y a su interpretación.

La idea del mercado simbólico resulta de utilidad para dar cuenta de la mayor o menor presencia de ciertos discursos en la vida social o del valor que éstos alcanzan en un momento determinado. No obstante, debemos tratar de evitar llevar esta idea hasta el extremo, cayendo en una interpretación elitista de la vida social, en la que sólo eclesiásticos, políticos, periodistas e intelectuales dominen el mercado y conviertan al común de los mortales en meros consumidores de la ideología que se les ofrece.

Moscovici (1984), defiende que tanto individuos como grupos piensan por sí mismos, produciendo y comunicándose incesantemente sus representaciones y las soluciones a las cuestiones que se plantean a sí mismos; produciendo en sus conversaciones y tertulias sus propias filosofías no- oficiales que tienen un impacto decisivo en sus relaciones sociales, su voto en las elecciones, el modo en que crían a sus hijos, planean su futuro, etc. Los acontecimientos, las ciencias y las ideologías, simplemente les suministran "alimento para el pensamiento".

A partir de este supuesto básico desarrolla su teoría de las representaciones sociales que, según él, tienen una naturaleza simbólica que se manifiesta en la acción, en el discurso y en los productos culturales. Estas representaciones sociales, por una parte, convencionalizan los objetos, personas y acontecimientos a los que se refieren, dándoles una forma definida, situándolos en una categoría, y estableciéndolos gradualmente como un modelo de cierto tipo, distinto y compartido por cierta gente. Los nuevos elementos con que se entra en contacto se adhieren a este modelo y se mezclan con él; de esta manera, cada experiencia se incorpora a una realidad predeterminada por convenciones, que claramente define sus límites, distingue lo significativo de lo no significativo y relaciona la parte con el todo, asignando a cada individuo a una categoría distinta. Estas representaciones constituyen para nosotros un tipo de realidad. Pero, además, estas representaciones son prescriptivas, se nos imponen con una fuerza irresistible, como consecuencia de la estructura simbólica y social presente antes incluso de que hayamos empezado a pensar. Son producto de elaboraciones y reelaboraciones que se dan en el tiempo como logros de sucesivas generaciones, de manera que no existe actividad social e intelectual amnésica.

No es fácil que palabras, ideas o seres no familiares se conviertan en usuales, próximos y factuales. Para darles un aspecto familiar hay que poner en marcha los dos mecanismos de un proceso de pensamiento basado en la memoria. El primer mecanismo busca 'anclar' ideas extrañas, reducirlas a categorías e imágenes ordinarias, asentarlas en un contexto familiar. El segundo mecanismo busca 'objetificarlas', es decir, convertir algo abstracto en algo casi concreto, transferir algo que está en la mente a algo que casi existe en el mundo físico. Ambos mecanismos buscan hacer familiar lo no familiar, y las representaciones son un resultado de su funcionamiento. Describamos brevemente estos dos procesos. 
Anclar. Es el proceso por el cual algo extraño y amenazante que nos intriga, se trae a nuestro particular sistema de categorías y se compara con el paradigma de una categoría que pensamos adecuada. Anclar es, pues, clasificar y nombrar algo. Lo no clasificado, lo innombrable es no-existente y además amenazante. Nombrar es también incluirlo en una jerarquía en la que todo tiene un valor positivo o negativo. Clasificar algo implica confinarlo a un conjunto de comportamientos y reglas que estipulan qué hacer o no hacer con los individuos pertenecientes a esa clase. Implica, también, elegir un paradigma (o prototipo) de entre los que tenemos almacenados en la memoria y establecer una relación positiva o negativa con él. Por eso se suele decir que reconocemos a alguien como miembro de un grupo, lo que representa una prioridad del predicado sobre el sujeto, del veredicto sobre el juicio. Esto tiene varias consecuencias. Primero, excluye la idea de percepción o pensamiento sin ancla. No tiene, así sentido hablar de sesgos en el pensamiento o la percepción, pues todo sistema de clasificación presupone una posición particular, un punto de vista basado en el consenso. Segundo, los sistemas de clasificación y nombrado no son modos de etiquetar $u$ ordenar personas u objetos, sino que su objetivo principal es facilitar la interpretación de características, la comprensión de las intenciones y motivos detrás de las acciones de la gente, de hecho, formar opiniones.

Objetificar es descubrir la cualidad icónica de una idea o un ser impreciso, reproducir un concepto en una imagen. No todas las palabras pueden ser transportadas a imágenes directamente, ya porque no haya suficientes imágenes 0 ya porque las que surgen son tabú. Las que pueden ser representadas se seleccionan y se integran en lo que Moscovici llama un patrón de núcleo figurativo, un complejo de imágenes que reproduce visiblemente un complejo de ideas. Una vez que una sociedad ha adoptado tal paradigma o núcleo figurativo, se hace más fácil hablar sobre aquello a lo que se refiere el paradigma y, por esta facilidad, las palabras que se refieren a él se usan más frecuentemente. Así surgen fórmulas y clichés que se suman a las imágenes previamente existentes. De este modo, ese paradigma figurativo toma una especie de independencia propia, apareciendo como un hecho inmediato, quedando suelto en la sociedad que lo acepta como una realidad, convencional, por supuesto, pero no por ello menos real.

En un segundo estadio la imagen se asimila totalmente y lo percibido reemplaza a lo concebido. Si la imagen existe, y se hace esencial para la comunicación y comprensión social es porque hay una realidad que lo sustenta. Dado que tiene que haber una realidad que la sustente, encontramos una realidad cualquiera para materializarla. Nuestro ambiente está en una parte muy importante compuesto de estas imágenes, y siempre estamos añadiendo y descartando imágenes.

Toda cultura tiene sus procedimientos para convertir sus representaciones en realidad (personas 0 animales han servido como elementos para un animismo que explica el comportamiento de los objetos; y, al revés, hay objetos que sirven para explicar el movimiento de los seres animados, en una especie de inversión del animismo). Ninguna cultura usa sólo un procedimiento, nosotros usamos expli-caciones mecanicistas, pero también personificamos conceptos abstractos (la cultura, la sociedad, los sentimientos, el estado, etc.), con lo que podemos convertirlos en sujetos con capacidad de acción (por lo menos en el plano gramatical), 0 sustantivizamos verbos, con lo que parece que existen substancias denotadas por esos nombres, pues las palabras no sólo nombran cosas, sino que contribuyen a crearlas y a dotarlas de características propias. Así los nombres que inventamos y creamos para dar una forma abstracta a substancias o fenómenos complejos, se convierten en la substancia 0 en el fenómeno, y ya nunca dejan de serlo (p.e., los héroes, la personificación de naciones, razas 0 clases). De este modo, la dimensión constitutiva de la realidad que tiene la retórica se convierte en algo 
extremadamente importante, pues hace posible construir ciertas repre-sentaciones que se nos presentan como reales (cfr., p.e.; Billig, 1987; Middleton y Edwards, 1990/1992).

En palabras del propio Moscovici (1984):

Entre la ilusión total y la realidad total hay una infinidad de gradaciones que deben tenerse en cuenta, puesto que nosotros las creamos, pero la ilusión y la realidad se alcanzan de la misma manera. La materiali-zación de una abstracción es una de las características más maravillosas del pensa-miento y el habla. Autoridades políticas e intelectuales de todo tipo, explotan esto para someter a las masas. En otras palabras, tal autoridad se basa en el arte de convertir una representación en la realidad de esa representación, la palabra para una cosa en una cosa para la palabra. (p. 38).

Estos conceptos de ancla y objetificación de la teoría de las representaciones mentales de Moscovici que acabamos de exponer, guardan una profunda semejanza con los de subjetivización y objetificación de Obeyesekere (1981), del que hacen uso Barclay y Smith (o.c.), si bien los primeros se refieren al ámbito de lo social, a las actividades y discursos públicos, mientras que los segundos conectan lo subjetivo con lo intersub-jetivo, viniendo a ser procesos simétricos entre sí, algo así como las pasarelas entre las culturas privadas y la cultura pública.

Tal interpretación tiene algunas consecuencias interesantes de cara a nuestra discusión. Por una parte, en lugar de "memoria colectiva", tal vez tendría más sentido hablar de "representaciones sociales del pasado" 0 , de forma más resumida, de "memoria social"4; y, por otra, se nos sugiere que esos procesos de co-construcción mutua de las culturas públicas y las culturas privadas sólo son posibles desde una cierta distancia entre ellas; es decir, situándose en una especie de "zona de desarrollo próximo" que haga posible la comunicación y la convencionalización, por parte de la cultura importadora (la que subjetifica, la que debe crear un nuevo "objeto") de nuevos significantes que viene de fuera y deben de llegar a convertirse en familiares.

Este último tema nos parece de especial interés, pues conduciría a la hipótesis de la necesidad de un cierto tempo para el cambio de las mentalidades. Un tempo y un ritmo que vendría dictado, como mínimo, por el tiempo preciso para cambiar las representaciones sociales $y$, con ellas - por definición - muchos de los elementos de las culturas personales de quienes viven en esas sociedades. Esto es algo que examinaremos a continuación.

\section{Cambios en la memoria social y ritmo de la Historia de las \\ me nta lidades: c o-construc ción}

mutua de la persona y la cultura

El siglo que está acabándose cuando estas líneas se escriben ha dejado algunas enseñanzas difíciles de olvidar por la cantidad de sangre que han costado. Entre ellas está que todo intento de revolución cultural, de eliminar de un plumazo valores y formas de vida tradicionales, no ha conseguido sus objetivos, pese al horror de las deportaciones en masa, los genocidios o los intentos de suprimir los rastros del pasado o las memorias sociales. Parece que los lazos culturales que mantienen unidos a etnias y naciones son muy resistentes al cambio y muy difíciles de sustituir. Ni los cambios de discurso, con todo el poder de la censura, ni la eliminación de monumentos y ritos, pudieron acabar con los sentimientos de las poblaciones, con la visión de su propio pasado, al haber mantenido algunas de sus visiones propias con un cierto éxito (cfr. Ahonen, 1992, 1997; Luczynski, 1997; Tulviste y Wertsch, 1994; Wertsch y Rozin, 1998). Parece como si el Volkgeist estuviera vivo en cada individuo, como si no se pudiera acelerar el pulso de la historia más allá de cierto ritmo ¿Cómo es esto posible?

4 . La expresión "memoria social", en lugar de "memoria colectiva", seguiría una lógica similar a la distinción que el mismo Moscovici hace de los términos social y colectivo en su discusión con Durkheim (cfr. Moscovici, 1984; Pereira y Vala, este volumen; de Rosa y Mormino, este volumen). 
No hay una respuesta simple a esta pregunta. Hasta ahora hemos venido ofrecido respuestas tentativas parciales en las que se contemplaba cómo la participación en las prácticas culturales de un determinado grupo hace posible implementar una estructura funcional particular en cada uno de los individuos participantes, lo que puede producir una cierta similitud en las estructuras cognitivas de una determinada población. Por otra parte, hemos explorado el papel de los artefactos culturales para la implementación, presentación y cambio de la identidad, además del papel de las prácticas sociales del recuerdo como una manera de poner en relación las memorias colectivas con las memorias autobiográficas, y a cómo esto afecta al desarrollo de la idea de un yo-mismo y de un nosotros-mismos. Hemos mencionado, también, que todos estos elementos toman una significación personal, tienen un valor emocional para los individuos, pero no hemos explorado como esto puede ser posible. Esto último es precisamente en lo que vamos a centrarnos ahora.

Tanto Barclay y Smith (o.c.), como Moscovici (o.c.) han utilizado el término convencionalización para referirse tanto al modo en que un nuevo significante va tomando un significado particular cuando se incorpora, tanto a la cultura personal, como a las representaciones sociales públicas. Este concepto de convencionalización tiene una larga tradición en ciencias sociales, habiendo sido acuñado en su origen por Haddon (1894) y Rivers (1912), y estando en el origen del programa de investigación de Bartlett que culminó con la publicación de Remembering (1932) ( Rosa, 1995).

Una de las características del enfoque de Bartlett era su énfasis en el valor afectivo, emocional, que percepciones e imágenes producen en el individuo. Estos afectos tienen una importancia de primer orden en el recuerdo, pero, también en el significado que se atribuye a las representaciones en el individuo, ya sean éstas una narración verbal o tengan una naturaleza imaginística, se produzcan en la percepción actual o sean resultado del recuerdo.

Una emoción es un evento fisiológico que se produce en un organismo, y que, a menudo, tiene una faceta fenomenológica, experiencial. Una emoción produce la activación del organismo, pero su lado fenomenológico afecta también a los procesos psicológicos en marcha en ese momento. No tiene, pues, nada de particular que el afecto, el lado evaluativo de la emoción, tiña cualquier acción que se esté llevando a acabo en ese momento, además de adherirse a los materiales psicológicos en ese momento presentes.

Rosa (1996) ofrece una discusión sobre las posibles implicaciones de estas tempranas contribuciones de Bartlett que tiene interés recoger aquí. Para Bartlett los recuerdos tienen una emoción asociada, de manera que reunir objetos mediadores del recuerdo tiene frecuentemente como objetivo precisamente revivir un determinado sentimiento. Por otra parte, los actos de recuerdo tienen un lado emocional, como también lo tienen las prácticas sociales del recuerdo en las que objetos, conceptos, individuos, 0 acontecimientos son evocados. Tal vez la capacidad de las narrativas para construir y preservar la identidad - ya se refieran éstas a acontecimientos pasados, a otros directamente experimentados 0 que pertenezcan a la memoria social, e incluso de una naturaleza mítica - esté muy relacionada con su poder de producir emociones compartidas en un grupo. Si éste es el caso, puede haber, entonces, una conexión no poco importante entre emoción y significado.

Bartlett (1923) indica que en cada grupo cultural las tendencias de acción humana toman una forma particular. Las costumbres, instituciones y hábitos de un grupo particular se muestran en las conductas individuales en forma de 'tendencias de acción', actuando como una "agencia definida que contribuye a la acción de ciertos resultados" (p. 270). El parentesco de este concepto con el de 'tendencia determinante' (Watt, 1905), o con el de actividad (Leontiev, 1975) que orienta 
(Galperin, 1976/1979) la acción del individuo, no se nos escapa. La tendencia humana más general e importante es el "esfuerzo hacia el significado" (Bartlett, 1916); el significado es algo tan importante en la vida psíquica que sin él, ni siquiera sería posible percibir. De acuerdo con su interpretación, la relación entre el acto de percibir y el objeto viene acompañada de un sentimiento, y "el sentimiento, sobre la repetición de la misma situación general, juega un papel director en la tendencia para reinstanciar el contenido" (p. 263). Los sentimientos no son, pues, un subproducto de la experiencia, sino que tienen un papel cognitivo fundamental. Son la función psicológica más temprana para la asimilación de una situación actual a una experiencia anterior. Sin embargo, los sentimientos son susceptibles de producir errores de reconocimiento, pues son reacciones a una situación y, por consiguiente, resulta fácil confundir una situación con otra cuando ambas despiertan el mismo sentimiento (Bartlett, 1925).

Desde el punto de vista de este autor, los afectos son reacciones orgánicas con una función adaptativa. El afecto aparece cuando cumple un papel en la conducta, cosa que sucede cuando varias tendencias coaparecen simultáneamente 0 entran en conflicto entre ellas, ya que cuando esto no sucede, la respuesta se produce sin dudar. Los afectos y sentimientos, estos últimos más aparentes para la conciencia, son pues como balizas de la presencia de una coaparición o conflicto entre tendencias.

El papel de las tendencias y de sus marcadores en la conciencia (afecto y sentimientos) es de primera importancia para la atribución de significado: "independientemente de cualquier otra cosa que sea cierta respecto del significado, estamos seguros de que el significado depende en mucho de la tendencia. Lo que una cosa indica, o si en absoluto indica algo, no es algo que dependa, en una parte muy importante, de las características externas de esa cosa, sino de la tendencia 0 actitud con la que se encuentra" (Bartlett, 1924, p. 287-288). El hecho de que un símbolo particular tenga un doble o un múltiple significado tiene su fundamentación psicológica en el hecho de que el mismo material cognitivo "puede apelar a más de un interés, y puede, al mismo tiempo, llamar a operar a dos 0 más tendencias" (1924, p. 280): a lo que hay que añadir que "no hay (...) ninguna tendencia en la vida humana real, que no sea ella misma un grupo de tendencias, un sistema, una organización, que tiene su peculiar cualidad y características" (ibídem, p. 280).

Desde este punto de vista se sigue que

el mecanismo de producción del símbolo es siempre el mismo. El material despierta una tendencia determinada, se atiende a él y se pone en relación con otro material para ayudar a formar un sistema mental particular. Al mismo tiempo, otra tendencia entra en juego, y con ello el mismo material consigue relaciones diferentes y un lugar en un sistema mental diferente. Los sistemas mentales, sin embargo, no están aislados normalmente, sino que están interrelacionados; primero, porque comparten materiales comunes, y segundo, porque entre todas las tendencias que tienen algún papel en su formación, una 0 dos son siempre determinantes. (Bartlett, 1924; p. 281)

Esta forma de concebir la función simbólica abre la posibilidad para que un individuo concreto construya su propio sistema de símbolos, al mismo tiempo que comparte la atribución de una significación particular a un material dado dentro de un conjunto de actividades sociales comunes. Pero, ¿qué es 10 que da estabilidad a un símbolo dentro de una cultura? Para esta pregunta, Bartlett dice, no hay una respuesta simple, pero "para la larga permanencia de un símbolo es casi una condición esencial que deba adherirse a algún sentimiento, o sentimientos, en lugar de a imágenes representativas directas. [...]. Los sentimientos son factores estabilizadores que ayudan a la conservación. Es más, resulta marcadamente fácil establecerlos mediante la 
educación, y pronto están firmemente arraigados. Una comunidad que desarrolla una tradición común, por su constitución desarrolla una considerable homogeneidad de carácter. Este es precisamente el tipo de grupo en el que los sentimientos, una vez establecidos, pueden fácilmente transmitirse de persona a persona, generación tras generación. Es a esto a lo que en una parte muy importante se debe la persistencia de los signos" (1924, p. 284). El significado, entonces, depende en mucho de las actividades sociales que dejan un rastro en cada individuo en forma de "tendencias de acción" cuyos marcadores intrapsicológicos son los afectos y los sentimientos.

Este papel de los sentimientos para el mantenimiento del significado de un símbolo es de importancia primordial para nuestra discusión. Bartlett sostiene que todo signo convencional tiene tanto un valor facial como un valor oculto. La persistencia del valor oculto de un signo depende de la permanencia de sentimientos estables. Cuando un nuevo símbolo reemplaza a otro viejo, los viejos sentimientos se adhieren al nuevo símbolo. El nuevo material despierta los viejos sentimientos, pero también previene que se expresen abiertamente. Al mismo tiempo, la materialidad concreta del símbolo ayuda a mantenerlo adherido a cuestiones concretas $y$, de esta manera, actúa como una herramienta para la preservación del grupo. Sin embargo, cuando se produce una situación de crisis, aparecen los viejos sentimientos que habían permanecido ocultos dentro de los nuevos símbolos, y con ellos el significado oculto se transporta de unas prácticas sociales antiguas a otras a lo largo del tiempo.

Esta manera de entender el simbolismo, y su permanencia y transformación a lo largo del tiempo, creemos que trata aspectos que resultan de interés para la discusión aquí en marcha. Por un lado, los restos del pasado, los monumentos, los relatos históricos (independientemente de su valor de verdad), los ritos, las prácticas del recuerdo, etc. no sólo tienen un significado explícito, sino que también acarrean otros ocultos a través de los sentimientos que son capaces de despertar en cada individuo perteneciente a una comunidad. De este modo se mantienen representaciones compartidas del pasado y símbolos de identidad que no tienen por qué coincidir ni con la materialidad ni con la interpretación históricamente "correcta" de eventos efectivamente acaecidos en el pasado, ni con características "reales" del ser colectivo que se experiencia como una palpable entidad natural.

Si no estamos equivocados en la interpretación que acabamos de ofrecer, no resulta sorprendente que sentimientos de identidad y modos de ser colectivos tengan una gran capacidad de permanencia, a pesar de cambios culturales, sociales y políticos bastante radicales. El universo simbólico, los mitos del pasado colectivo, la propia idea del "nosotros" colectivo resultan extremadamente resistentes a la substitución de unos significantes por otros, aunque eso no quiere decir que el cambio sea imposible, pues la Historia nos muestra cómo etnias y naciones se crean, se transforman 0 llegan a disolverse. Lo que sí parece claro es que no resulta fácil imponer cambios culturales, ni alterar las ideas constitutivas que las personas de una comunidad tengan sobre su propio ser, aunque se utilicen métodos muy brutales. La modificación de las señas de identidad no sólo pasa por el cambio de una simbología sino, también, por el de los mismos significados que se transportan, que deben ser convencionalizados en la comunidad que los utiliza, y entrar en la dinámica afectiva de los elementos de la cultura de ese grupo.

En cualquier caso, resulta claro que en nuestras sociedades contemporáneas existe una enorme polifonía de voces, con múltiples identidades entrecruzadas, formas de discurso contradictorias, mercados simbólicos que se solapan, distintas formas de valorar los mismos productos simbólicos. En definitiva, muchos subgrupos y diálogos entrecruzados y, con ellos, muchas formas de atesorar, recuperar e interpretar las memorias del pasado colectivo, entre los cuales están las enseñanzas de las asignaturas de historia y los productos de la 
práctica disciplinada de los historiadores. Esta multiplicidad, lejos de ser entendida como una cacofonía que ha de ser uniformada, reducida a una línea monódica, es una muestra de riqueza cultural, una garantía de dinamismo social. Pero, al mismo tiempo, representa un reto social, cultural y político, pues estas diferentes posturas deben de ser armonizadas en la vida común mediante un conjunto de reglas que permitan el disenso, sin llegar al enfrentamiento; entre éstas, sin duda, debe estar la elaboración de sistemas de valoración de diferentes tipos de discursos sobre el pasado, basados en la verificabilidad, además de modos democráticamente reglados de gestionar los conflictos.

Si bien es cierto que los productos de la investigación histórica y los recuerdos de la memoria difícilmente llegarán a coincidir, tampoco lo es menos que no puede haber futuro sin memoria, a pesar de los problemas que acarrean las inevitables distorsiones de ésta. Lo que nos conduce a una hipótesis que no por vieja deja de asombrarnos una y otra vez: la Historia, entendida ahora como el curso de las acciones humanas a través del tiempo, es un producto de la acción acumulada del hombre. Podemos no creer en los grandes relatos transcendentales, pero en el diá- logo entre los pequeños relatos que se entrecruzan en los recuerdos colectivos está el germen realizativo de lo que será el futuro.

Nuestros actos del presente, entre los cuales están lo que decidimos recordar, tienen una inevitable dimensión moral; no sólo describen lo que se hizo, lo que fuimos, lo que somos y cómo lo somos, sino que también abren algunas perspectivas sobre nuestro ser futuro, a la vez que restringen posibilidades de lo que podemos llegar a ser. La memoria - y aún más cuando ésta es colectiva no es sólo una condición necesaria de la identidad, sino que es también un requisito para la preparación del futuro. Aunque todos los recuerdos sean actos situados, realizados desde un cierto punto de vista $-y$ en ese sentido estén inevita-blemente sesgados - lo menos que podemos exigir a los interlocutores que participan en la memoria social es que no inventen ni cultiven mitos sobre el pasado, ni tampoco pretendan silenciar las voces que evocan incómodos re-cuerdos. No es tolerable el intento de imponer recuerdos u olvidos obligatorios. Puesto que un futuro compartido en paz sólo es posible desde una memoria colectiva consensuada, resulta imprescindible negociar interpretaciones comunes del pasado desde la voluntad de una recon-ciliación en el presente.

\section{Referencias}

Ahonen, S. (1992). Clio sans uniform. A study of the post-Marxist transformations in the history curricula in East Germany and Estonia (1986-1991). Annales Academiae Scientiarum Fennicae B:264. J yväskylä: Gummerus.

AHONEN, S. (1997). A Transformation of History. The Official Representation of History in East Germany and Estonia (1986-1991). Culture and Psychology 3(1), 41-62.

Albert, S. (1984). The Sense of Closure. En En K.J. Gergen y M.M. Gergen (eds.): Historical Social Psychology. Hillsdale (N.J .): Lawrence Erlbaum Associates.

Apel, K.O. (1975/1997). El camino del pensamiento de Charles S. Peirce. Madrid: Visor.

Bakhtin, M.M. (1981). The Dialogic Imagination: Four Essays by M.M. Bakhtin. De. Michael Holquist. Austin: Austin University Press.

Bakhurst, D. (1990/1992). La memoria social en el pensamiento soviético. En D. Middleton y D. Edwards (eds.) Memoria Compartida. Barcelona: Paidós.

Bakhurst, D. y Sypnovich, C. (eds.) (1995). The Social Self. Londres: Sage. 
Barclay, C.R. y Smith, T.S. (1992). Autobiographical Remembering: Creating Personal Culture. In M.A. Conway, D.C. Rubin, H. Spinnler And W.A. Wagenaar (Eds.). Theoretical Perspectives on Autobiographical Memory, 75-97. Dordrecht: Kluwer Academic Press.

Bartlett, F.C. (1916). An experimental study of some problems of perceiving and imaging. British J ournal of Psychology, 8, 222-266.

Bartlett, F.C. (1923). Psychology and Primitive Culture. Nueva York: MacMillan.

Bartlett, F.C. (1924). Symbolism in Folk Lore. Proceedings of the VIlth International Congress of Psychology. Cambridge: Cambridge University Press.

Bartlett, F.C. (1925). Feeling, imaging and thinking. British J ournal of Psychology, 16, 16-28.

Bartlett, F.C. (1932/1995). Remembering. A Study in Experimental and Social Psychology. Cambridge: Cambridge University Press. Versión española titulada Recordar. Madrid: Alianza.

Baumeister, R.F. y Hastings, S. (1997). Distortions of Collective Memory. How Groups Flatter and Deceive Themselves. En J.W. Pennebaker, D. Páez y B. Rimé (eds.). Collective Memory of Political Events. Mahwa (N.J .): Lawrence Erlbaum.

Billig, M. (1987). Arguing and Thinking. Cambridge: Cambridge University Press.

Billig, M. (1995). Banal Nationalism. Londres: Sage.

Bourdieu, P. (1991). Language and Symbolic Power. Cambridge, Mass. Harvard University Press.

Certeau, M. de (1980/1984). The practice of everyday life. Berkeley: University of California Press.

Cole, M. (1999). Psicología Cultural. Madrid: Morata.

Csikszentmihalkyi, M. y Beattie, O.V. (1979). Life themes: A theoretical and empirical exploration of their origins and effects. J ournal of Humanistic Psychology, 19, 45-63.

Fivush, R. y Reese, E. (1991). The social construction of autobiographical memory. En M.A. Conway, D.C. Rubin, H. Spinnler yW.A. Wagenaar (eds.): Theoretical perspectives on autobiographical memory. Dordrecht: Kluwer.

Galperin, P.Y. (1976/1979). Introducción a la Psicología: Un Enfoque Dialéctico. Madrid: Pablo del Río.

Gergen, M.M. \& Gergen, K.J . (1984). The Social Construction of Narrative Accounts. En K.J . Gergen y M.M. Gergen (eds.): Historical Social Psychology. Hillsdale (N.J. .): Lawrence Erlbaum Associates.

Haddon, A.C. (1894). Decorative Art in British New Guinea. Cunningham Memoirs, n1 10. Royal Irish Academy.

Halbwachs, M. (1925): Les cadres sociaux de la mémoire. Paris: Alcan.

Halbwachs, M. (1950): La mémoire collective. Presses Universitaires de France. (2ème éd. Paris: Presses Universitaires de France, 1968.

Hedetoft, U. (1995). Signs of Nations. Aldershot: Dartmouth.

J anet, P. (1928). L'Evolution de la mémoire et de la notion de temps. Paris:

Kim, U. \& Berry, J.W. (1993). Introduction. In U. Kim \& J.W. Berry (eds.). Indigenous Psychologies. Research and Experience in Cultural Context, 1-29. London: Sage.

Laboratory of Comparative Human Cognition (1982). A M odel System for the Study of Learning Difficulties. Quarterly Newsletter of the Laboratory of Comparative Human Cognition, 4 (3), 39-66.

Latour, B.(1991). We have never been modern. London: Harvester Wheatsheaf.

Leontiev, A.N. (1931). Razvitie Pámiat. Moscú.

Leontiev, A.N. (1975). Activity, Consciousness and Personality. Englewood Cliffs, N.J .: Prentice-Hall. 
Luria, A.R. (1932). The Nature of Human Conflicts. New York: Liveright

Luczynski, J . (1997). The Multivoicedness of Historical Representations in a Changing Sociocultural Context: Young Polish Adults' Representations of World Warr II. Culture and Psychology 3(1), 21-40.

Mannheim, K. (1946). Ideology and Utopia. An Introduction to the Sociology of Knowledge. Nueva York: Harcourt, Brace \& Co.

Mathien, T. (1991). History and the Moralist. The Monist 74(2), 240-267.

McClelland, J .L.; Rumelhart, D.E. y Hinton, G.E. (1986). The Appeal of Parallel Distributed Processing. En D.E. Rumelhart, J .L. McClelland and the PDP Research Group: Parallel Distributed Processing. Explorations in the Microstructure of Cognition. Cambridge, Mass.: The M.I.T. Press.

Mead, G.H. (1909). Social Psychology as Counterpart to Physiological Psychology. Psychological Bulletin, 6 (1), 401-411.

Mead, G.H. (1913). The Social Self. J ournal of Philosophy, 10. 374-380.

Middleton, D. y Edwards, D. (1990/1992). Collective Remembering. London: Sage. Versión española titulada Memoria compartida. Barcelona: Paidós.

Moscovici, S. (1984). The phenomenon of Social representations. En R.M. Farr y S. Moscovici (eds.). Social representations. Cambridge: Cambridge University Press y Paris: Maison des Sciences de l'Homme, pp. 3-70.

Obeyesekere, G. (1981). Medusa's hair: an essay on personal symbols and religious experience. Chicago: Chicago University Press.

Pepper, S.C. (1942/1966). World Hypothesis: A Study on Evidence. Berkeley: University of California Press.

Radley, A. (1990/1991). Artefactos, memoria y sentidos del pasado. En D. Middleton y D. Edwards (eds.): Memoria compartida: La naturaleza social del recuerdo y el olvido. Barcelona: Paidls.

Riba, C. (1990). La Comunicación Animal. Un enfoque zoosemiótico. Barcelona: Anthropos.

Riba, C. (1994). Zoosemiotics and the Study of Animal Communication. The other Semiotic Project. En A. Rosa y J . Valsiner (eds.). Explorations in Socio-Cultural Studies, Vol.1. Historical and Theoretical Discourse. Madrid: Fundación Infancia y Aprendizaje.

Ricoeur, P. (1991). Narrative identity. En D. Wood (Ed.). On Paul Ricoeur: Narrative and interpretation. London, Routledge.

Rivers, W.H. (1912). Conventionalism in primitive art. Reports of British Association for the Advancement of Science (Secciln H), 599.

Rosa, A. (1994a). A reflection on the construction of socio-historical discourse. Levels and units of analysis. Socio-Cultural Research News 1(2), 4-6.

Rosa, A. (1994b): What do people consume history for? (If they do). Learning history as a process of knowledge consumption and construction of meaning. In M. Carretero y J. Voss (comp.): Learning Processes in History and Social Sciences. Hillsdale, N.J .: Lawrence Erlbaum.

Rosa, A. (1995). "Remembering y la obra de Frederick C. Bartlett. Introducción a la edición española" de F. C. Bartlett: Recordar. Madrid: Alianza, pp. 9-43.

Rosa, A. (1996). Bartlett's Psycho-Anthropological Project. Culture and Psychology 2(2), 355-378

Rosa, A.; Blanco, F.; Huertas, J .A.; Mateos, A.I. y Díaz, F. (1995). Acts of Identification and the Games of Identity. Comunicación presentada en International Workshop on National and Cultural Identity. Universidad Autónoma de Madrid. Miraflores de la Sierra, Madrid.

Rosa, A.; Huertas, J .A. y Blanco, J .A. (1993). Psicología de la Ceguera y Psicología General. En A. Rosa y E. Ochaita (eds.). Psicología de la ceguera. Madrid: Alianza.

Rosa, A.; Huertas, J A. y Blanco, F. (1996). Metodología de Historia de la Psicología. Madrid: Alianza. 
Rosa, A. y Simón, C. (1996). Description, Prescription and change. Developmental Psychology as a Cultural Artifact. Polish Quarterly of Developmental Psychology 2(3), 191-203.

Rumelhart, Smolenski, McClelland \& Hinton (1986). Schemata and Sequential Thought Processess in PDP Models. En D.E. Rumelhart, J .L. McClelland and the PDP Research Group: Parallel Distributed Processing. Explorations in the Microstructure of Cognition. Cambridge, Mass.: The M.I.T. Press.

Sheriff, J.K. (1989). The Fate of Meaning. Princeton: Princeton University Press.

Smith, (1991). National Identity. London: Penguin.

Smolenslki, P. (1988). On the proper treatment of Connectionism. The Behavioural and Brain Sciences, 11, 1-74.

The Oxford Universal Dictionary Illustrated on Historical Principles. (1974). Oxford: Oxford University Press.

Tulviste, P. \& Wertsch, J.V. (1994). Official and Unofficial Histories: The Case of Estonia. J ournal of Narrative and Life History 4(4), 311-329.

Turner, J.C. (1985). Social categorisation and the self-concept: A social cognitive theory of group behaviour. En E.J . Lawler (ed.): Advances in group processes (vol. 2, pp. 77-121). Greenwich, CT: J Al Press.

Turner, J .C. \& Oakes, P.J . (1986). The significance of the social identity concept for social psychology with reference to individualism, interactionism and social influence. British J ournal of Social Psychology, 25, 237-352.

Valsiner, J. (1987). Culture and the Development of Children's Actions. A Cultural-Historical Theory of Developmental Psychology. Chichester: J ohn Wiley \& Sons.

Vygotski, L.S. (1934/1993). Pensamiento y Lenguaje. Incluido en L.S. Vygotski: Obras Escogidas, Vol. II. Madrid: AprendizajeVisor.

Vygotski, L.S. (1978/1979). El desarrollo de los procesos psicollgicos superiores. Barcelona: CrRtica.

Vygotski, L.S. (1982/1991a). Sobre los sistemas psicollgicos. En Obras escogidas. Tomo I. Madrid: M.E.C.-Visor.

Vygotski, L.S. (1982/1991b). El significado histlrico de la crisis en PsicologRa. En Obras escogidas. Tomo I. Madrid: M.E.C.-Visor.

Watt, H.J . (1905). Experimentelle Beitr@ge zur eine Theorie des Denkens. Archiv gesamte Psychologie, 4, 289-436.

Wertsch, J.V. (1991). Voices of the Mind. Cambridge, Mass.: Harvard University Press.

Wertsch, J.V. (1994). Struggling with the Past: Some Dynamics of Historical Representation. In M. Carretero \& J. .F. Voss (Eds.). Cognitive and Instructional Processes in History and the Social Sciences. Hillsdale, N.J .: Lawrence Erlbaum.

Wertsch, J.V. (1997). Narrative Tools of History and Identity. Culture and Psychology3(1), 5-20.

Wertsch, J.V. y Rozin, M. (1998). The Russian revolution. Official and Unofficial Accounts. En J. Voss y M. Carretero (eds.). Learning and Reasoning in History. London: Woburn Press.

Wertsch, J.V.; Tulviste, P. \& Hagstr'm, F. (1994). A Sociocultural Approach to Agency. In E. Forman, N. Minick and C.E. Stone (Eds.). Knowledge Construction and Social Practice: Institutional and Interpersonal Contexts of Human Development. New York: Oxford University Press.

White, H. (1973). Metahistory. Baltimore: The J ohn Hopkins Universty Press.

Wundt, W. (1912-13/1926). Elementos de Psicología de los Pueblos. Madrid: Daniel J orro.

Zinchenko, P.I. (1939/1983). The problem of involuntary memory. Soviet Psychology, 22, 55-111. 